Improvements in plate anchor capacity due to cyclic and maintained loads combined with consolidation

Z. Zhou/C. D. O’Loughlin/D. J. White/S. A. Stanier

August 2019

\title{
Improvements in plate anchor capacity due to cyclic and maintained loads combined
} with consolidation

\author{
Manuscript submitted to Géotechnique
}

Z. Zhou, C. D. O’Loughlin, D. J. White and S. A. Stanier

\section{Zefeng ZHOU (corresponding author)}

Centre for Offshore Foundation Systems and ARC Research Hub for Offshore Floating Facilities

University of Western Australia

Perth, WA 6009, Australia

Tel: +61 403848151

Email: zefeng.zhou@research.uwa.edu.au

\section{Conleth D. O'LOUGHLIN}

Centre for Offshore Foundation Systems and ARC Research Hub for Offshore Floating Facilities

University of Western Australia

Perth, WA 6009, Australia

Tel: +61 864887326

Email: conleth.oloughlin@uwa.edu.au

\section{David J. WHITE}

University of Southampton and ARC Research Hub for Offshore Floating Facilities

Southampton, Southampton SO17 1BJ, UK

Tel: +4423 80596859

Email: david.white@soton.ac.uk

\section{S. A. STANIER}

University of Cambridge and ARC Research Hub for Offshore Floating Facilities

Cambridge CB2 1PZ, UK

Tel: +44 7856009042

Email: sas229@cam.ac.uk

Number of words (excluding the abstract, list of notation, acknowledgements, references, tables and figure captions): $\quad 7026$

Number of tables (excluding appendix): 4

Number of figures (excluding appendix): 15 
Improvements in plate anchor capacity due to cyclic and maintained loads combined with consolidation

\section{Changes in plate anchor capacity under maintained and cyclic loading due to} consolidation effects

\section{Z. Zhou ${ }^{1}$, C. D. O'Loughlin ${ }^{1}$, D. J. White ${ }^{2}$ and S. A. Stanier ${ }^{3}$}

Plate anchor technology is an efficient solution for mooring offshore floating facilities for oil and gas or renewable energy facilities. The anchor is typically subjected to a maintained load component and intermittent episodes of cyclic loading throughout the design life. These loads, and the associated shearing, remoulding and consolidation processes, cause changes in the anchor capacity, particularly in soft fine-grained soils. The changing anchor capacity affects the mooring performance by changing the safety margin and also the overall system reliability. In this paper the changing anchor capacity in reconstituted normally-consolidated natural carbonate silt was assessed through a series of beam centrifuge tests on horizontally loaded circular plate anchors. The results demonstrate that full consolidation under a typical maintained load leads to a 50\% gain in the anchor capacity, and subsequent cyclic loading and reconsolidation can triple this increase. An effective stress framework based on critical state concepts is employed to explain and support the experimental observations. This study shows that when viewed from a whole-life reliability perspective, maintained and cyclic loading provide a long-term enhancement of anchor capacity in soft fine-grained soils. This beneficial effect is currently overlooked in design practice, but can be predicted using the framework shown here, which can form the basis for a digital twin that monitors the through-life integrity of a plate anchor.

Keywords: Plate anchor, anchor capacity, consolidation, cyclic loading, centrifuge test, effective stress, digital twin.

\footnotetext{
${ }^{1}$ Centre for Offshore Foundation Systems, The University of Western Australia, Crawley, WA 6009, Australia (Corresponding author: Fax +61 403848151; Email: zefeng.zhou@research.uwa.edu.au)

${ }^{2}$ University of Southampton, Southampton SO17 1BJ, UK

${ }^{3}$ University of Cambridge, Cambridge CB2 1PZ, UK
} 
Improvements in plate anchor capacity due to cyclic and maintained loads combined with consolidation

\section{INTRODUCTION}

The offshore energy industry is increasingly reliant on floating facilities to exploit oil, gas, wind, tidal and wave energy resources. Floating facilities are kept on station using mooring lines that terminate at anchors in the seabed. The mooring line load includes maintained and cyclic components that are resisted by a combination of the submerged weight of the mooring in the water column, the seabed friction that develops between the mooring line and the seabed and by mobilisation of soil strength around the anchor.

The loading transferred to the anchor changes the strength of the seabed around the anchor over its design life. The weakening effect of cyclic loading on soil strength is well recognised in current design practice, and methodologies for quantifying the cyclic 'fatigue' of soil are well developed (e.g. Andersen et al., 1988; Andersen, 2015). However, over the operating period of the facility, dissipation of excess pore pressure will occur, which can result in a regain in soil strength. This consolidation effect on soil strength and anchor capacity is commonly overlooked, but can be important and beneficial for design practice.

This paper considers these effects through a series of centrifuge tests and retrospective numerical simulations of an embedded plate anchor subjected to differing combinations of consolidation and cyclic load. Our focus is on plate anchors, rather than pile anchors (driven, suction or gravity installed), which is motivated by their low cost and high performance (O’Loughlin et al. 2018, Aubeny 2018). For example, the follower used to install the plate anchor (e.g. a suction pile, Wilde et al. 2001), can be reused and the holding capacity of a plate is high relative to the weight of the anchor (O’Loughlin et al. 2015, 2017).

Plate anchor capacity under undrained, unconsolidated seabed conditions has been well established through model testing (e.g. Gaudin et al. 2006, Blake et al. 2010, O’Loughlin et al. 2014), medium- to large-scale field testing (e.g. Dahlberg \& Strom 1999, Heyerdahl \& Eklund 2001, Wilde et al. 2001, Blake et al. 2015, O’ Loughlin et al. 2016) and analytical and numerical modelling (e.g. Martin and Randolph 2001, Wang et al., 2010, 2013; Wang \& O’Loughlin 2014; Yu et al., 2011; Liu et al. 2017). This work has validated the rigorous plasticity solutions and other numerical results that can be used to link the in situ soil undrained strength to the initial monotonic bearing capacity of an embedded plate. Quantifying changes in plate anchor capacity due to the evolution of soil strength under more realistic long term loading has received much less attention, with the exception of Wong et al. (2012) and Han (2016) who present experimental data of gains in capacity resulting from monotonic loading. 
Improvements in plate anchor capacity due to cyclic and maintained loads combined with consolidation

However, over the life of a typical floating facility, moorings experience many episodes of cyclic loading associated with changing wave or wind conditions. The background maintained load may also slowly vary, for example with the loading or ballast condition of the floating system. As a result of this complex time-varying load, changes in anchor capacity are expected to be more significant than observed in previous experiments.

There is significant value in quantifying these changes in capacity both as part of the design process, and for asset management during operation of a moored facility. For design, the reliability of the system is affected by both improvements in performance (such as these gains in anchor capacity) as well as degradation (such as from corrosion of the mooring line). Both positive and negative effects should be considered to reach an accurate assessment of the system reliability and the true probability of failure. Meanwhile, during operation, a model that tracks the changing capacity of the anchor as a result of the environmental conditions experienced, provides a basis for reassessing the mooring capacity if design inputs are altered (e.g. the maximum expected storm load is updated) or if a life extension is required. Such a model can form a 'digital twin' (Sharma et al. 2017, Grieves \& Vickers 2017) of the anchor, to extend current usage of digital twinning (i.e. establishing virtual models of a physical asset) for asset management of floating systems (e.g. Renzi et al. 2017).

This paper provides experimental data on the changing capacity of an embedded plate anchor in normally consolidated calcareous silt due to episodes of maintained and cyclic load. These data are simulated via a digital twin of the centrifuge test that uses the effective stress framework set out by Zhou et al. (2019a) to calculate the changing soil strength due to undrained shearing and consolidation.

\section{EXPERIMENTAL PROGRAMME}

\subsection{Geotechnical centrifuge facility}

The experiments were performed in the $3.6 \mathrm{~m}$ diameter beam centrifuge at the University of Western Australia (Randolph et al., 1991) at an acceleration level of 150g. The test programme involved four anchor tests with differing loading sequences and a suite of in-flight characterisation tests to provide geotechnical properties to assist interpretation of the anchor tests, including selection of model parameters for the analytical framework used for backanalysis. The anchor tests involved horizontal loading of a vertically oriented plate anchor (i.e. with no prescribed changes in embedment depth) with a mixture of consolidation and one-way cyclic loading phases. T-bar penetrometer tests were performed with equivalent cyclic loading 
Improvements in plate anchor capacity due to cyclic and maintained loads combined with consolidation

phases, to explore the comparative changes in soil strength in similar penetrometer and anchor tests.

\subsection{Soil sample}

The soil sample was prepared from bulk samples of a natural carbonate silt retrieved from offshore Australia with the geotechnical properties summarised in Table 1. The silt was reconstituted as a slurry with a water content of $145 \%$ and poured into a sample container measuring 650 by $390 \mathrm{~mm}$ in plan and $325 \mathrm{~mm}$ deep. The sample was consolidated under selfweight in the centrifuge at an acceleration of 150g for 5 days, during which time additional slurry was added to achieve a final sample height of approximately $210 \mathrm{~mm}$. A $35 \mathrm{~mm}$ layer of free water was maintained at the sample surface to ensure saturation. The average effective unit weight of the sample was established from moisture content determinations made on cores taken from other centrifuge samples of the same soil subjected to the same sample preparation procedures (Chang et al. 2019; Chow et al. 2019; Zhou et al. 2019b). This was necessary as no undisturbed locations remained after the testing described in this paper. Over the range of vertical effective stress levels relevant to the anchor tests, the initial moisture contents were in the range 65 to $88 \%$, with an average effective unit, $\gamma^{\prime}=5.2 \mathrm{kN} / \mathrm{m}^{3}$.

\subsection{Model anchor and test setup}

\subsubsection{Model anchor and load cell}

The circular anchor plate was stainless steel with diameter, $D_{\mathrm{a}}=35 \mathrm{~mm}$ and thickness, $t_{\mathrm{a}}=3$ $\mathrm{mm}$. The projected area of the plate anchor is $\sim 22 \mathrm{~m}^{2}$ in equivalent prototype scale, which is within the range used in practice, e.g. 16 to $44 \mathrm{~m}^{2}$ for SEPLAs (Cassidy et al. 2012; Brown et al. 2010) and 7 to $30 \mathrm{~m}^{2}$ for drag-embedded vertically loaded plate anchors (Vryhof, 2006). The anchor was loaded using a $1.2 \mathrm{~mm}$ diameter stainless steel wire. The applied load was measured at the anchor using a miniature load cell (6 $\mathrm{mm}$ in diameter and $12 \mathrm{~mm}$ long) with a measurement range of $1.5 \mathrm{kN}$ (Figure 1). The anchor displacement was measured using the encoder located on the vertical axis of the actuator used to pull on the loading wire, with small corrections applied to account for system compliance.

\subsubsection{Experimental arrangement and procedures}

Figure 2 shows the experimental arrangement during the installation and preparation stages of the tests, which involved the following steps that were undertaken with the centrifuge stopped: 
Improvements in plate anchor capacity due to cyclic and maintained loads combined with consolidation

1. Before installing the anchor a vertical slot was cut in the consolidated sample using a 3 $\mathrm{mm}$ thick steel plate for the anchor loading line to pass through (Figure 2a). Verticality and positioning of this slot was ensured by two steel guides that were mounted on the sample container.

2. A pulley arrangement was installed at one end of the sample container, with the anchor loading line and load cell cable threaded through (Figure 2b).

3. The anchor was installed using a mandrel mounted on the vertical axis of the actuator at $0.1 \mathrm{~mm} / \mathrm{s}$ (Figure 2c). A slight tension was maintained on the loading line and load cell cable to ensure that they followed the anchor into the slot created in Step 1.

4. The electrical actuator was then positioned on cross beams spanning the width of the sample container, and the anchor loading line connected to the actuator's vertical axis, in order to apply horizontal loading to the anchor (Figure 2d).

The initial anchor embedment (measured to the centre of the circular plate, see Figure 2d) was $z=150 \mathrm{~mm}$ for all anchor tests, equivalent to $z / D_{a}=4.3$. This embedment depth was selected to target a 'deep' flow-round response so that the soil deformation remained local to the anchor, rather than reaching either the soil surface or the bottom (sand) boundary (1.7Da from the centre of the plate). Numerical simulations reported by $\mathrm{Yu}$ et al. (2015) confirm these dimensions are appropriate, aided by the strength gradient in the sample, which causes the failure mechanism to become one-sided, skewing towards the weaker soil (i.e. towards shallower depths).

By installing the anchor at $1 \mathrm{~g}$ such that it would translate without rotation when loaded, it was possible to quantify the effects of cyclic loading and consolidation without the complicating effects of installation and subsequent rotation (keying) of the anchor. However, we began each test with a monotonic pull to failure, to represent in a repeatable way some level of installationinduced disturbance.

After installation of the anchor and loading system, the centrifuge was spun to $150 \mathrm{~g}$ and a period of three hours allowed before starting the anchor test. Each anchor test involved combinations of monotonic, maintained and/or cyclic loading. Details relevant to each of these loading stages are provided below.

- Monotonic loading. Each anchor test involved an initial monotonic stage where the anchor was loaded in displacement control at a velocity, $v=1 \mathrm{~mm} / \mathrm{s}$, such that the dimensionless group, $v D_{\mathrm{a}} / c_{\mathrm{op}}=92$ (using an 'operative' coefficient of consolidation, 
Improvements in plate anchor capacity due to cyclic and maintained loads combined with consolidation $c_{\mathrm{op}}=4 \mathrm{~m}^{2} /$ year from piezo-foundation dissipation data presented later) so the response is undrained (House et al. 2001, Randolph and Hope 2004, Colreavy et al. 2016). This monotonic stage was maintained until the anchor capacity became steady (which occurred within $<2.5 D_{\text {a }}$ of movement). This steady anchor capacity was used as the reference undrained unconsolidated anchor capacity, $q_{\mathrm{a}, \mathrm{uu}}$, for defining the subsequent maintained and cyclic loading phases. A final monotonic stage was also conducted after the maintained and/or cyclic loading phase of the test, using the same velocity, $v=1$ $\mathrm{mm} / \mathrm{s}$, for an anchor displacement that was sufficient to observe the peak anchor capacity.

- Maintained loading. This stage of the anchor tests involved operating the actuator in load control to maintain an anchor resistance equal to half of that measured in the initial monotonic stage (i.e. $q_{\mathrm{a}}=0.5 q_{\mathrm{a}, \mathrm{uu}}$ ) for a period of 3 hours. This consolidation period was sufficient for about 95\% dissipation of excess pore pressure, as estimated using consolidation data described later.

- Cyclic loading. The cyclic loading stage of the anchor tests involved 1080 cycles (to reflect a typical number of cycles for a three hour design storm), of loading from $0.25 q_{\mathrm{a} \text {,uu }}$ to $0.75 \mathrm{q}_{\mathrm{a}, \mathrm{uu}}$. The frequency of the cycles was $0.4 \mathrm{~Hz}$, and was selected as a balance between being able to achieve high quality load control and ensuring undrained conditions. In a single load cycle the dimensionless time, $T=c_{\mathrm{op}} t / D_{\mathrm{a}}{ }^{2}=0.0003$ (using $c_{\text {op }}=4 \mathrm{~m}^{2} /$ year) and so the drainage within a single cycle was negligble.

\subsection{Soil characterization}

\subsubsection{Undrained shear strength}

A model scale T-bar penetrometer (Stewart \& Randolph, 1991) with a diameter, $d=5 \mathrm{~mm}$ and a length of $20 \mathrm{~mm}$ was used to determine profiles of intact and remoulded shear strength. Two 'standard' T-bar tests (TB_01 and TB_02) involving undrained penetration (at $v=3 \mathrm{~mm} / \mathrm{s}$ such that $v d / c_{\mathrm{h}}=40$, where $c_{\mathrm{h}}=12 \mathrm{~m}^{2} /$ year; see Figure 7) and cyclic phases gave the profiles of undrained shear strength, $s_{\mathrm{u}}$, shown in Figure 3a, where $s_{\mathrm{u}}$ was interpreted using a constant Tbar capacity factor of 10.5 (Martin and Randolph, 2006). The profiles are fitted by:

$s_{\mathrm{u}, \mathrm{i}}=k \mathrm{Z}$

where $s_{u, i}$ is the initial undrained shear strength and $k$ is the strength gradient with (prototype) 
Improvements in plate anchor capacity due to cyclic and maintained loads combined with consolidation

depth. As shown in Figure 3a, $k=2 \mathrm{kPa} / \mathrm{m}$, which gives a normally-consolidated shear strength ratio, $\left(s_{\mathrm{u}} / \sigma_{\mathrm{vo}}^{\prime}\right)_{\mathrm{NC}}=0.38$, which is slightly higher than $\left(s_{\mathrm{u}} / \sigma^{\prime}{ }_{\mathrm{vo}}\right)_{\mathrm{NC}}=0.32$ determined from simple shear tests (Chow et al. 2019). The cyclic episode of the T-bar test progressively remoulds the soil, degrading the undrained shear strength towards the fully remoulded strength, with the limiting value of $S_{\mathrm{u}, \mathrm{cyc}} / S_{\mathrm{u}, \mathrm{i}}$ indicating a soil sensitivity, $S_{\mathrm{t}} \sim 5$, where $S_{\mathrm{t}}$ is the ratio between the in-situ and fully remoulded undrained shear strengths (Figure 3b).

The second group of T-bar tests included a cyclic episode with 1080 load-controlled cycles (i.e. equal to the cycles imposed in the anchor tests), between either $0.25 s_{\mathrm{u}, \mathrm{i}}$ and $0.75 s_{\mathrm{u}, \mathrm{i}}$ (Test TB_03) or 0 and $0.75 s_{u, i}$ (Test TB_04) at an initial depth, $z=52 \mathrm{~mm}$. The cyclic load amplitude in TB_03 is consistent with the anchor tests, and TB_04 explores a higher amplitude. A loading frequency of $1 \mathrm{~Hz}$ ensured an undrained response within each cycle, while ensuring accurate load control. In both tests there is a local increase in soil strength after cyclic loading, with peak values of $s_{\mathrm{u}}=44.5 \mathrm{kPa}$ in TB_03 (Figure 4a) and $s_{\mathrm{u}}=55 \mathrm{kPa}$ in TB_04 (Figure 4b), which are about 2.5 and 2.75 times higher than the initial soil strength at the same depth.

The two groups of T-bar tests demonstrate that whilst cyclic remoulding leads to a significant reduction in soil strength (TB_01 and TB_02), one-way cyclic loading to much lower shear strains but over a longer time period causes a significant gain in soil strength. This is due to dissipation of the excess pore pressure induced by the cyclic loads - which is equally relevant to anchor loading.

\subsubsection{Consolidation characteristics}

Consolidation coefficients for the carbonate silt were determined from the excess pore pressure dissipation stages of piezocone and piezo-foundation tests conducted at various penetration depths (for the piezocone) and various stress levels (for the piezo-foundation).

In piezocone dissipation tests the pore water flow is primarily radial, controlled by the coefficient of horizontal consolidation, $c_{\mathrm{h}}$. Dissipations were conducted at depths, $z=30,70$, 110 and $150 \mathrm{~mm}$ (equivalent to $\sigma_{\mathrm{v}}^{\prime} \sim 23,55$, 85 and $117 \mathrm{kPa}$, respectively) and are shown in Figure 5 with results in the same soil reported by Chow et al. (2019). Excess pore pressure, $u_{\mathrm{e}}$, is normalised by the initial value, $u_{\mathrm{e}, \mathrm{i}}$, and plotted against dimensionless time

$T^{*}=\frac{c_{\mathrm{h}} t}{R^{2} \sqrt{I_{r}}}$

where $R$ is the piezocone radius $=5 \mathrm{~mm}$, and the rigidity index, $I_{\mathrm{r}}=G / \mathrm{s}_{\mathrm{u}}$, uses an elastic shear modulus, $G$, estimated using (Mahmoodzadeh et al. 2015) 
Improvements in plate anchor capacity due to cyclic and maintained loads combined with consolidation

$G=\frac{3(1-2 v)}{2(1+v)} \frac{p^{\prime}(1+e)}{\kappa}$

257

258

259

260

261

where $v$ is Poisson's ratio, $\kappa$ the slope of the swelling line, $p^{\prime}$ the mean effective stress and $e$ the void ratio. Equation 3 together with the $s_{\mathrm{u}}$ profiles on Figure 3 gives $I_{\mathrm{r}}=110$. Values of $c_{\mathrm{h}}$ were determined by matching $T_{50}^{*}$ from the experimental dissipation curves with that from the Teh \& Houlsby (1991) theoretical solution.

Consolidation around a circular plate anchor involves both radial and vertical drainage, so piezo-foundation tests were undertaken to indicate this 'operative' coefficient of consolidation, $c_{\mathrm{op}}$. The rigid circular piezo-foundation had a diameter, $D_{\mathrm{f}}=40 \mathrm{~mm}$, and was instrumented with a pore pressure transducer (PPT) in the centre of the underside of the foundation (Cocjin et al., 2014; Colreavy et al. 2016). The piezo-foundation test involved staged loading to $q_{\text {app }}=$ $12 \mathrm{kPa}, 40 \mathrm{kPa}, 80 \mathrm{kPa}$ and $160 \mathrm{kPa}$, with a dissipation stage at each load. The normalised pore pressure, $u_{\mathrm{e}} / u_{\mathrm{e}, \mathrm{i}}$, measured at $q_{\mathrm{app}}=12,40,80$ and $160 \mathrm{kPa}$ are plotted with dimensionless time, $T=c_{\mathrm{op}} t / D_{\mathrm{f}}{ }^{2}$, in Figure 6 together with corresponding finite-element solutions for a rigid circular surface foundation (Gourvenec and Randolph, 2010).

The measured coefficients of consolidation, $c_{\mathrm{h}}$ and $c_{\mathrm{op}}$ demonstrate the expected dependence on stress level (Figure 7) with $c_{h} / c_{\text {op }} \sim 3$ due to the lower stiffness and higher permeability associated with radial flow. A value of $c_{o p}=4 \mathrm{~m}^{2} /$ year is applicable at the anchor test depth and has been used throughout the interpretation.

\subsection{Anchor test programme}

The four anchor tests are summarised in the Table 2. Each test involved an initial monotonic phase to measure the 'undrained-unconsolidated' anchor capacity, $q_{\mathrm{a}, \mathrm{uu}}$. Thereafter, the loading sequences employed in each of the four anchor tests differed as described below and as shown in Figure 8:

Test 1 (Figure 8a) involved a consolidation period during which the anchor load was maintained at $0.5 q_{\mathrm{a} \text {,uu }}$ for 3 hours.

Test 2 (Figure 8b) involved a cyclic episode, with the cyclic load varying in the range $0.25 q_{\mathrm{a}, \mathrm{uu}}$ to $0.75 q_{\mathrm{a} \text {,uu }}$ over 1080 cycles.

Test 3 (Figure 8c) was a combination of Tests 1 and 2, with an initial consolidation period followed by a cyclic episode and a final consolidation period.

Test 4 (Figure 8d) repeated Test 3 five times.

Each test ended with a displacement-controlled monotonic stage (using the same velocity, $v=$ 
Improvements in plate anchor capacity due to cyclic and maintained loads combined with consolidation

$1 \mathrm{~mm} / \mathrm{s}$ as in the initial monotonic stage) to measure the change in anchor capacity due to the prior loading.

\section{ANCHOR TEST RESULTS}

\subsection{Undrained-unconsolidated anchor capacity}

291 The resistance during the initial monotonic phase is shown in Figure 9, with anchor resistance 292 expressed as the dimensionless factor:

293

$N_{\mathrm{c}, \mathrm{a}}=\frac{q_{\mathrm{a}}}{s_{\mathrm{u}, \mathrm{i}}}$

294

where $s_{\mathrm{u}, \mathrm{i}}$ is the initial soil strength at the anchor mid-height (i.e. at a depth $z=150 \mathrm{~mm}$ ) and $q_{\mathrm{a}}$ is the anchor resistance (i.e. the measured anchor load divided by $A=\pi \mathrm{D}_{a}{ }^{2} / 4$ ). Each test showed an initial peak in resistance, reducing to a steady value. The initial peak reflects the localised increase in soil strength due to dissipation of installation-induced excess pore pressure, with anchor capacity stabilising (after a displacement of $x / D_{\mathrm{a}} \sim 1.5$ ) in the range $N_{\mathrm{c} \text {,a }}$ $=10.8$ to 11.5 for the four tests. These values are slightly lower than the exact solution for an infinitesimally thin deeply embedded plate, which gives $N_{\text {c,a }}=12.42$ for a smooth interface and $N_{\mathrm{c}, \mathrm{a}}=13.11$ for a rough interface (Martin and Randolph, 2001), although numerical results in Wang et al. (2010) and Wang and O'Loughlin (2014) suggest that these values would be approximately $9 \%$ higher for the $t / D_{\mathrm{a}}$ in the centrifuge tests. The seemingly low experimental $N_{\text {c,a }}$ values may be due to the choice of T-bar capacity factor used to determine $s_{\mathrm{u}}$, noting that $\left(s_{\mathrm{u}} / \sigma^{\prime}{ }_{\mathrm{vo}}\right)_{\mathrm{NC}}=0.32$ from the simple shear tests on the same soil (Chow et al. 2019) would require $s_{\mathrm{u}}$ on Figure 3a to be $\sim 20 \%$ lower. In this case the experimental $N_{\mathrm{c}, \mathrm{a}}$ values would be higher by the same amount, and in better agreement with numerically determined values. Regardless of the bearing factor, the steady resistance on the T-bar and the plate is very similar, consistent with other studies (e.g. Chung \& Randolph 2004).

\subsection{Effects of maintained load, cyclic loading and reconsolidation on anchor capacity}

311 The anchor response during the various loading sequences are shown in Figure 10 and the time

312 histories of displacement and load are provided in Figure 11. The resulting capacities are

313 referred to as 'consolidated-undrained' $\left(q_{\mathrm{a}, \mathrm{cu}}\right)$ for tests involving only maintained load, and 314 'cyclic-consolidated-undrained' $\left(q_{\mathrm{a}, \mathrm{ccu}}\right)$ for tests that include cycling and also consolidation 315 (either during the cycling or a separate period of maintained load).

316 In Test 1 , a maintained load of $q_{\mathrm{a}}=0.5 q_{\mathrm{a} \text {,uu }}$ was applied for 3 hours, which is equivalent to a 
Improvements in plate anchor capacity due to cyclic and maintained loads combined with consolidation Z. Zhou/C. D. O’Loughlin/D. J. White/S. A. Stanier

317

318

319

320

321

322

323

324

325

326

327

328

329

330

331

332

333

334

335

336

337

338

339

340

341

342

343

344

345

346

dimensionless time factor, $T=t c_{\mathrm{op}} / D_{\mathrm{a}}{ }^{2}=1.12$. This is sufficient time for $\sim 95 \%$ dissipation of excess pore pressure, as established pore pressure measurements on a deeply embedded plate in the same soil (Zhou et al. 2019b). The resulting capacity is $q_{\mathrm{a}, \mathrm{cu}}=780 \mathrm{kPa}\left(q_{\mathrm{a}, \mathrm{cu}} / s_{\mathrm{u}, \mathrm{i}}=17.4\right)$, which is a $51 \%$ increase relative to $q_{\mathrm{a} \text {,uu }}=516 \mathrm{kPa}$ (Figure 10). The anchor displacement during the consolidation phase was $x=0.1 D_{\mathrm{a}}$, and was practically complete after 1.5 hours, consistent with the estimated consolidation duration (Figure 11a).

Test 2 showed a similar gain in capacity after the 1080 load cycles (over 40 minutes), with a capacity of $q_{\mathrm{a}, \mathrm{ccu}}=737 \mathrm{kPa}\left(q_{\mathrm{a}, \mathrm{ccu}} / s_{\mathrm{u}, \mathrm{i}}=16.4\right)$, which is a $50 \%$ increase over $q_{\mathrm{a}, \mathrm{uu}}=489 \mathrm{kPa}$ (Figure 10). The anchor displacement was more significant $\left(x=1.25 D_{\mathrm{a}}\right)$ although the position stabilised as consolidation occurred (Figure 11b).

Tests 3 and 4 showed even greater gains in anchor capacity. Test 3 combined the maintained and cyclic loading phases employed in Tests 1 and 2, arranged as a 3 hour maintained load, followed by 1080 cycles and a final 3 hour maintained load (see Figure 8c). Test 4 involved the same pattern of loading as Test 3, but was repeated five times (see Figure 8d).

Test 3 resulted in a capacity of $q_{\mathrm{a}, \mathrm{ccu}}=990 \mathrm{kPa}\left(q_{\mathrm{a}, \mathrm{ccu}} / \mathrm{s}_{\mathrm{u}, \mathrm{i}}=22.2\right)$, which is almost double the undrained unconsolidated capacity, $q_{\mathrm{a}, \mathrm{uu}}=521 \mathrm{kPa}\left(q_{\mathrm{a}, \mathrm{uu}} / s_{\mathrm{u}, \mathrm{i}}=N_{\mathrm{c}, \mathrm{a}}=11.6\right)$. In Test 4 , the five episodes of consolidation and cyclic loading further enhanced the strength gain to $q_{\mathrm{a}, \mathrm{ccu}}=1230$ $\mathrm{kPa}\left(q_{\mathrm{a}, \mathrm{ccu}} / s_{\mathrm{u}, \mathrm{i}}=27.5\right)$, which is 2.5 times the initial $q_{\mathrm{a}, \mathrm{uu}}=492 \mathrm{kPa}\left(q_{\mathrm{a}, \mathrm{uu}} / s_{\mathrm{u}, \mathrm{i}}=N_{\mathrm{c}, \mathrm{a}}=11\right)$.

The total anchor displacement in Tests 3 and Test 4 was $x \sim 0.1 D_{\mathrm{a}}$, with practically all of this displacement occurring during the initial consolidation phase, consistent with Test 1 . The displacement during subsequent cyclic loading stages was smaller than in Test 2 (which had no initial maintained load period) because the cyclic loads were a lower proportion of the current anchor capacity.

The observed gains in anchor capacity due to consolidation under maintained and cyclic loading is consistent with the hardening behaviour in the cyclic (load-controlled) T-bar tests. In both cases, excess pore pressure from continuous one-way cyclic loading or maintained load dissipates, causing a gain in soil strength. The T-bar tests show that a higher load amplitude leads to a higher strength gain (Figure 4). The anchor tests show that additional cycles lead to higher capacity gains (Figure 10). Both effects are consistent with the level of pore pressure generation driving the level of subsequent strength gain. 
Improvements in plate anchor capacity due to cyclic and maintained loads combined with consolidation

\section{BACK ANALYSIS USING EFFECTIVE STRESS FRAMEWORK}

348 In this section, the effective stress framework described in Zhou et al. (2019a) is applied to simulate the change in anchor capacity due to the load sequences applied. Calculation of anchor capacity, $q_{\mathrm{a}}$, requires selection of an anchor capacity factor, $N_{\mathrm{c}, \mathrm{a}}$, and the current undrained shear strength, $\mathrm{s}_{\mathrm{u}}$ :

$q_{\mathrm{a}}=N_{\mathrm{c}, \mathrm{a}} S_{\mathrm{u}}$

353

354

355

356

357

358

359

360

361

362

363

364

365

366

367

368

369

370

371

372

373

374

375

376

377

Changes in foundation capacity can be interpreted solely as changes in soil strength, because any changes in the failure mechanism caused by the changing soil strength have minimal influence on the bearing factor $N_{\mathrm{c}, \mathrm{a}}$ (Stanier \& White 2019). The framework, therefore, focuses solely in the variation in $s_{\mathrm{u}}$, in order to predict changes in $q_{\mathrm{a}}$.

\subsection{Summary of framework}

The framework is developed using critical state concepts, and is designed as the simplest basis for capturing changes in strength through a linear profile of soil due to development and subsequent dissipation of excess pore pressure. For the anchor tests, the soil domain is a horizontal row of elements. Vertical effective stress and soil strength is calculated at each soil element throughout the loading sequence (Figure 12a). The framework breaks the event time history into undrained cycles - which generate pore pressure - and consolidation periods during which pore pressure dissipates.

Example effective stress paths illustrate the framework (Figure 12b). Development of excess pore pressure during undrained shearing leads to a reduction in effective stress at constant specific volume. The maximum excess pore pressure (and hence the lowest effective stress) is associated with fully remoulded conditions, reached at the remoulded state line (RSL, e.g. AC). This state is reached during the cyclic remoulding phase of TB_01 and TB_02 (Figure 3b). More moderate excess pore pressure generation, such as that developed during the cyclic loading in TB_03 and TB_04 (Figure 4), causes a reduction in effective stress to a point between the NCL and the RSL (e.g. D-E and F-G). During either partial consolidation (path EF) or full consolidation (path C-D), dissipation of excess pore pressure leads to an increase in effective stress and a reduction in specific volume following the unload-reload line (URL). The effective stress will either return to the initial value (e.g. point D) or potentially to a higher effective stress state if the consolidation phase involves a maintained load (e.g. point I).

The components of the framework analysis as applied to the anchor are summarized below, 
with further details provided in Zhou et al. (2019a):

- Excess pore pressure generation and effective stress. The excess pore pressure, $u_{\mathrm{e}}(\hat{x})$ $\left(\hat{x}=x / D_{\mathrm{a}}\right)$, is generated at a rate linked to the shear strain, $\varepsilon$, at each soil element. The rate of excess pore pressure generation is highest at the initial stress state $\left(\sigma_{\mathrm{v} 0}^{\prime}=\gamma^{\prime} z\right.$ on the NCL for a normally consolidated soil) and close to zero as the vertical effective stress approaches the RSL (point A-B in Figure 12b) (Zhou et al. 2019a). The vertical effective stress on the RSL, $\sigma^{\prime}{ }_{v, R S L}$, can be expressed directly in terms of the initial specific volume as

$\sigma_{\mathrm{v}, \mathrm{RSL}}^{\prime}(\hat{x})=\left(\frac{s_{\mathrm{u}}}{\sigma_{\mathrm{vo}}^{\prime}}\right)_{\mathrm{NC}} \frac{\sigma_{\mathrm{vo}}^{\prime}}{\Phi S_{\mathrm{t}}} \exp \left\{\frac{\Lambda\left[\Gamma_{\mathrm{NCL}}-v_{\mathrm{i}}(\hat{x})-\lambda \ln \left(\sigma_{\mathrm{vo}}^{\prime}\right)\right]}{\lambda-\kappa}\right\}$

where $\left(s_{\mathrm{u}} / \sigma_{\mathrm{v} 0}^{\prime}\right)_{\mathrm{NC}}$ is the normally consolidated undrained strength ratio; $\Lambda$ is the plastic volumetric strain ratio; $\Gamma_{\mathrm{NCL}}$ is the specific volume at $\sigma^{\prime}{ }_{\mathrm{v}}=1 \mathrm{kPa}$ on the NCL; $v_{\mathrm{i}}$ is the initial specific volume; $\kappa$ is the gradient of the unloading-reloading line (URL); $\lambda$ is the gradient of the NCL; $S_{\mathrm{t}}$ is the soil sensitivity and $\Phi$ is a lumped strength parameter.

The excess pore pressure generation rate is:

$\frac{\delta u_{\mathrm{e}}(\hat{x})}{\delta \varepsilon(\hat{x})}=\frac{\chi}{\varepsilon_{98}}\left[\frac{u_{\mathrm{e}, \mathrm{r}}(\hat{x})}{u_{\mathrm{e}, \max }(\hat{x})}\right]^{p}$

where

$$
\chi=\frac{\left(1-0.01^{1-p}\right)}{1-p} u_{\mathrm{e}, \max }(\hat{x})
$$

and $\varepsilon_{98}$ is the characteristic shear strain associated with a degree of remoulding equal to $98 \%$; $p$ is a constant power that affects the shape of the pore pressure generation; $\chi$ is a characteristic pressure that varies with specific volume, $v$. The rate is proportional to $u_{\mathrm{e}, \mathrm{r}} / u_{\mathrm{e}, \max }$ which varies from unity down to zero as pore pressure builds up. $u_{\mathrm{e}, \max }$ is the maximum pore pressure, given by the difference between the equilibrium stress, $\left(\sigma^{\prime}{ }_{\mathrm{v} \text {,eqm }}\right.$ $\left.=\sigma^{\prime}{ }_{\text {vo }}+\sigma_{\mathrm{a}}\right)$ and $\sigma_{\mathrm{v}, \mathrm{RSL}}^{\prime}$, while $u_{\mathrm{e}, \mathrm{r}}$ is the remaining potential excess pore pressure, $\left(\sigma_{\mathrm{v}^{-}}\right.$ $\sigma^{\prime}{ }_{v, R S L}$ ) (distance B-C on Figure 12b). The incremental (absolute) shear strain is calculated as the anchor moves horizontally with a given displacement, $\delta \hat{x}$, and weighted by the strain influence function, $\mu(\hat{x})$, with boundaries that extend a normalised distance $\beta$ ahead and behind the anchor (Zhou et al. 2019a). Any maintained load on the anchor generates additional stress that is added to the vertical self-weight stress to enhance the equilibrium effective stress in the ground. This extra stress, at 

position $\delta$ relative to the anchor, is $\sigma_{\mathrm{a}}=I_{\sigma} K_{o} q_{\text {a }}$ where $I_{\sigma}(\delta)$ is the influence factor describing the stress distribution away from the anchor following Boussinesq (1885) and Poulos \& Davis (1974); $K_{\mathrm{o}}$ is a general earth pressure coefficient and $q_{\mathrm{a}}$ is the maintained load.

- Consolidation process. Dissipation of excess pore pressure during consolidation is described by a simple hyperbolic model (Chatterjee et al. 2013; Zhou et al. 2019a), which is expressed in rate form as

$\frac{\delta u_{\mathrm{e}}(\hat{x})}{\delta t}=-\frac{u_{\mathrm{e}, \mathrm{i}}(\hat{x}, t) c_{\mathrm{op}}^{\mathrm{m}} t^{\mathrm{m}-1}\left(D_{a}^{2} T_{50}\right)^{\mathrm{m}} \mathrm{m}}{\left[\left(D_{a}^{2} T_{50}\right)^{\mathrm{m}}+\left(c_{\mathrm{v}} t\right)^{\mathrm{m}}\right]^{2}}$

where $t$ is the period of (consolidation) time, $c_{\mathrm{op}}$ is the operative coefficient of consolidation, $m$ is a constant that controls the shape of the dissipation response and $T_{50}$ is the dimensionless time factor for $50 \%$ dissipation of the initial excess pore pressure.

- Soil strength response. The current undrained shear strength at each soil element is calculated from the vertical effective stress, $\sigma_{\mathrm{v}}^{\prime}(\hat{x})$, via a lumped strength parameter, $\Phi$ :

$s_{\mathrm{u}}(\hat{x})=\Phi \sigma_{\mathrm{v}}^{\prime}(\hat{x})$

An average undrained shear strength mobilised by the anchor, $s_{\mathrm{u}, \mathrm{av}}$, is obtained by integrating the undrained shear strength within an influence zone (described by $v_{\mathrm{s}}(\hat{x})$ ) with a triangular weighting function extending a distance, $\alpha$, behind and in front of the anchor:

$s_{\mathrm{u}, \mathrm{av}}=\int_{\widehat{x_{\mathrm{m}}}-\alpha}^{\widehat{x_{\mathrm{m}}}+\alpha} s_{\mathrm{u}}(\hat{x}) v_{\mathrm{s}}(\hat{x}) d x$

Prior to failure, a proportion of the strength, $s_{\mathrm{u}, \mathrm{mob}}$, is progressively mobilised with a changing tangent stiffness, expressed as

$\delta\left(\frac{s_{\mathrm{u}, \mathrm{mob}}}{s_{\mathrm{u}, \mathrm{av}}}\right)=\delta(\hat{x}) K$

where

$K=\left(1-\left(\frac{\Delta\left(\frac{s_{\mathrm{u}, \mathrm{mob}}}{s_{\mathrm{u}, \mathrm{av}}}\right)}{\Delta\left(\frac{s_{\mathrm{u}, \mathrm{max}}}{s_{\mathrm{u}, \mathrm{av}}}\right)}\right)^{\zeta}\right) K_{\max }$

in which $\zeta$ is the power law parameter to account for the nonlinear change in tangent 
Improvements in plate anchor capacity due to cyclic and maintained loads combined with consolidation

stiffness; $\left(\frac{s_{u, m a x}}{s_{u, a v}}\right)$ is the potential change after any reversal; the effective tangent stiffness, $K$, varies nonlinearly from a maximum stiffness, $K_{\max }$ to 0 at $s_{\mathrm{u}, \mathrm{mob}} / s_{\mathrm{u}, \mathrm{av}}=1$ (see Zhou et al. 2019a for further details).

\subsection{Selection of framework parameters}

The model parameters used in the simulations are summarised in Table 3. Many parameters are directly defined in the experiments, e.g. the anchor diameter, effective soil unit weight, over-consolidation ratio and soil sensitivity. The critical state soil parameters $\left(\kappa, \lambda\right.$ and $\left.\Gamma_{\mathrm{NCL}}\right)$ are established from oedometer tests (Table 1) and the normally consolidated undrained shear strength ratio $\left(\mathrm{s}_{\mathrm{u}} / \sigma_{\mathrm{v} 0}^{\prime}\right)_{\mathrm{NC}}$ from the initial penetration of a T-bar test.

The excess pore pressure generation parameters $\left(\varepsilon_{98}, p\right.$ and $\left.\beta\right)$ were obtained by fitting to the cyclic T-bar results shown in Figure 3. Excess pore pressure dissipation parameters, $T_{50}$ and $m$ were taken from previous back-analyses of a circular plate at a normalised depth, $z / D_{a}=3.5$ in the same soil (Zhou et al. 2019b). This requires selection of an 'operative' coefficient of consolidation, $c_{\mathrm{op}}$, as $T_{50}=t_{50} C_{\mathrm{op}} / D_{\mathrm{a}}{ }^{2}$ (where $t_{50}$ is actual, rather than dimensionless time). Figure 7 indicates $c_{\text {op }}=4 \mathrm{~m}^{2} /$ year (Figure 7) for this soil and anchor geometry. For field applications, $c_{\text {op }}$ may be selected as an average of $c_{\mathrm{v}}$ from Rowe-cell (or oedometer) tests and $c_{\mathrm{h}}$ from a piezocone or piezoball test.

The final group of parameters in Table 3 control the strength and stiffness mobilization response. The lumped strength parameter was taken as $\Phi=1.62$, selected by scaling $\left(s_{\mathrm{u}} / \sigma_{\mathrm{v} 0}^{\prime}\right)_{\mathrm{NC}}$ by the ratio of the drained to undrained T-bar penetration resistance ( 4.2 for this soil, from Chow et al. (2019)). The extent of the strength influence zone was taken as $\alpha=0.5$ (i.e. $0.5 D_{\mathrm{a}}$ ), consistent with the size of the failure mechanism for a deeply buried plate (e.g. Yu et al. 2011, Wang and O’Loughlin, 2014), and equal to the value in previous analyses of spudcan penetration (Zhou et al. 2019a). For the simulation of the episodic T-bar test, a value of $\alpha=1$ was selected meaning that the operative strength was calculated over a zone that extended by one bar diameter away from the centerline, matching the size of numerically-observed failure mechanisms (Einav \& Randolph, 2005; Zhou et al. 2019a).

460 The maximum stiffness, $K_{\max }$ and its decay parameter, $\zeta$, were taken as 210 and 4.55 respectively, based on a best fit to the cyclic phase of Test 2 . These final two parameters were the only ones fitted directly to the anchor test results. All other parameters have been sourced from the T-bar results, theoretical considerations, or other previously-published tests. 
Improvements in plate anchor capacity due to cyclic and maintained loads combined with consolidation

\subsection{Results of T-bar test simulations}

465

466

467

468

469

470

471

472

473

474

475

476

477

478

479

480

481

482

483

484

485

486

487

488

489

490

491

492

493

The framework performance is first demonstrated via simulations of an episodic T-bar test that was performed in the same sample as the anchor tests following the protocol set out by Hodder et al. (2008). This type of test involves undrained penetration (at $v=3 \mathrm{~mm} / \mathrm{s}$ ) to a depth, $z=75$ $\mathrm{mm}$, followed by three episodes of 20 displacement-controlled cycles over $z=30$ to $75 \mathrm{~mm}$ after which the T-bar was maintained at the base of the cycles for a period of one hour.

The simulation used the parameters set out in Table 3 and the full procedures are described in Zhou et al. (2019a), who report equivalent tests and simulations in kaolin clay.

The simulated and measured profiles of penetration resistance are compared in Figure 13a, with the mid-cycles values of $s_{\mathrm{u}} / s_{\mathrm{u}, \mathrm{i}}$ highlighted in Figure 13b. The degradation and recovery of strength are both well captured and the strength at the start of the third episode has nearly recovered to the initial value.

\subsection{Results of anchor test simulations}

The anchor capacity is the product of a bearing factor and an average undrained strength around the anchor. Specific bearing factors were taken for each test $\left(N_{\mathrm{c}, \mathrm{a}}=11.5,10.9,11.6\right.$ and 11 for Tests 1, 2, 3 and 4) based on the initial monotonic loading stage ( Table 2). These values were used in the simulations of each test to separate out these minor test-to-test variations in anchor capacity from the changes in capacity within each test.

The framework, using the parameters listed in Table 4, was then employed to calculate the operative soil strength and therefore the anchor resistance throughout each test.

\subsubsection{Changes in anchor capacity}

Figure 14 compares the simulated and measured evolution of anchor capacity for each test. Overall the simulations provide good agreement with the measurements with the peak resistance predicted to within $7 \%$ on average (Table 2). There is a tendency to underestimate the post-peak resistance, which is perhaps because the model does not capture the strengthened soil being moved forward with the anchor.

An additional simulation was undertaken to illustrate the limiting peak anchor capacity by extending Test 4 to 200 episodes of cyclic loading and reconsolidation. By the end of this simulation, the capacity reached $q_{\mathrm{a}, \mathrm{ccu}}=2070 \mathrm{kPa}$, which is $>4$ times more than the initial $q_{\mathrm{a} \text {,uu }}$. This example illustrates the potential for even greater gains in anchor capacity than were 
Improvements in plate anchor capacity due to cyclic and maintained loads combined with consolidation

observed in the relatively short term centrifuge model tests.

This additional simulation illustrates the potential for the model to be used to maintain an updated value of the anchor capacity, in response to the whole life loading it has experienced. The movements of a floating facility are commonly monitored and used to estimate loading and fatigue within the facility and its mooring system (e.g. Renzi et al. 2017). Similarly, the motions or mooring loads could be fed into this anchor model, in order to maintain a continuously updated estimate of the changing capacity. The model then becomes a digital twin of the anchor, to support integrity management, design condition updating and life extensions.

\subsubsection{Variation in effective stress and voids ratio}

Figure 15 shows the variation in effective stress and specific volume calculated by the framework for soil elements at various locations relative to the anchor, which are indicated in Figure 14 for each test. Observations from these stress paths include:

- Test 1 (Figure 15a). Effective stress paths are provided for soil elements at two locations; $x / D_{\mathrm{a}}=0$, in front of the plate at the end of the initial monotonic stage, and $x / D_{\mathrm{a}}=0.26$, which is at the plate as the peak anchor capacity is mobilised during the post-consolidation monotonic stage. During the initial monotonic loading phase, excess pore pressure develops, reducing $\sigma_{\mathrm{v}}^{\prime}$ from point $\mathrm{A}^{\prime}$ to point $\mathrm{B}^{\prime}\left(\right.$ at $x / D_{\mathrm{a}}=0$ ) and point $\mathrm{B}$ (at $x / D_{\mathrm{a}}=0.26$ ). The vertical effective stress at point $\mathrm{B}$ is higher than at point $\mathrm{B}^{\prime}$ as this soil element is initially further from the anchor. During the consolidation phase the effective stress path follows the URL (B-C or B'-C') and then the NCL to point D or D'. The final monotonic stage causes excess pore pressures to redevelop, such that $\sigma_{\mathrm{v}}^{\prime}$ reduces to points $\mathrm{E}^{\prime}$ and $\mathrm{E}$ for $x / D_{\mathrm{a}}=0$ and $x / D_{\mathrm{a}}=0.26$ respectively. Points B' (at $\left.x / D_{\mathrm{a}}=0\right)$ and $\mathrm{E}\left(\right.$ at $\left.x / D_{\mathrm{a}}=0.26\right)$ represent the difference in stress state between the initial and final monotonic stages. As the effective stress at point $\mathrm{E}$ is higher than at point B', the soil strength, and hence the anchor capacity is higher.

- Test 2 (Figure 15b). Three soil elements are shown for this test, due to the high horizontal displacement: $x / D_{\mathrm{a}}=0,0.45$ and 1.2. The response at $x / D_{\mathrm{a}}=0$ matches Test 1 (Figure 15a), with $\sigma_{\mathrm{v}}^{\prime}$ reducing from A" to B". The effective stress at $x / D_{\mathrm{a}}=0.45$ reduces very slightly from A' to B', being at the edge of the strain influence zone. The stress at $x / D_{\mathrm{a}}=1.2$ is unaffected, being outside the strain influence zone during this stage.

During cyclic loading the soil elements respond according to their location relative to 

that of the plate. The effective stress initially reduces at $x / D_{a}=0$, but then begins to increase (at $N=35$ ) as excess pore pressure dissipation outweighs the continuing generation. After 170 cycles $x / D_{\mathrm{a}}=0$ is outside the strain influence zone, so only dissipation occurs thereafter, following the URL to point C". At $x / D_{\mathrm{a}}=0.45$ the modest pore pressure from the initial monotonic stage (point B') is followed by significant additional pore pressure generation during the initial cycles. However, after $N=180$ $\sigma_{\mathrm{v}}^{\prime}$ starts to increase with the dissipation process outweighing the generation. By $N=$ $1080, x / D_{\mathrm{a}}=0.45$ is almost outside the strain influence zone, so the stress path is dominated by dissipation towards $C^{\prime}$. The soil element at $x / D_{\mathrm{a}}=1.2$ only enters the strain influence zone at $N=270$, and $\sigma_{\mathrm{v}}^{\prime}$ initially reduces until $N=430$. Thereafter, the stress increases to point $\mathrm{C}$ following a path that is approximately parallel to the NCL and RSL.

During the final monotonic stage the soil elements at $z / D_{a}=0$ and 0.45 do not respond as they are not within the strain influence zone, whereas at $z / D_{\mathrm{a}}=1.2 \sigma_{\mathrm{v}}^{\prime}$ reduces to point $\mathrm{D}$, at a higher vertical effective stress than at point $\mathrm{B}$ and consequently a higher soil strength.

- Test 3 (Figure 15c). Effective stress paths at $x / D_{\mathrm{a}}=0$ and 0.26 are shown, consistent with Test 1 . The responses at $x / D_{\mathrm{a}}=0$ and 0.26 for the initial monotonic stage and the maintained load stage (to D' and D) match Test 1 . As in Test 2, cyclic loading causes an initial reduction and then increase in effective stress, with both soil elements responding to the cycle-by-cycle change in pore pressure over the complete 1080 cycles. The plate movement in this test is significantly reduced relative to Test 2 because of the consolidation during the initial maintained load stage. The magnitude of pore pressure at each soil element depends on their location relative to the plate. The effective stress path for the final maintained load stage of the test follows the URL along $\mathrm{E}^{\prime}-\mathrm{F}^{\prime}\left(x / D_{\mathrm{a}}=0\right)$ and E-F $\left(x / D_{\mathrm{a}}=0.26\right)$, reaching slightly different limiting effective stresses ( $F^{\prime}$ and $F$ ) due to the different (horizontal) position of each element relative to the anchor, and therefore different values of $\sigma^{\prime}{ }_{\text {v,eqm }}$.

The final monotonic stage of the test causes a reduction in $\sigma_{v}^{\prime}$ to point $G^{\prime}$ or $G$ which are higher than at point B', yielding a gain in anchor capacity.

- Test 4 (Figure 15d and Figure 15e - extended). As for Test 3, soil elements at $x / D_{\mathrm{a}}=0$ and 0.26 are shown. The initial response matches Test 3 , and then continues by repeating the episodes of cyclic loading and maintained load. Progressively less excess 
Improvements in plate anchor capacity due to cyclic and maintained loads combined with consolidation pore pressure is generated, such that the eventual effective stress state (point $\mathrm{H}$ for $x / D_{\mathrm{a}}$ $=0.26$ ) is at a high effective stress and hence soil strength. An extended simulation of the same test involving 200 episodes of cyclic and maintained load (Figure 15e) illustrates the progressive decay in excess pore pressure generation as $u_{\mathrm{e}, \max }$ reduces from $\sim 179 \mathrm{kPa}$ in the first episode to $\sim 19 \mathrm{kPa}$ in the final episode. The limiting soil strength is at $\sigma_{\mathrm{v} \text {,eqm }}^{\prime}$ on the RSL, which corresponds to a soil strength that is 6.9 times the initial undrained soil strength (point B). This ratio exceeds the ratio of drained to undrained penetration resistance for this soil $\left(\Phi /\left(\mathrm{s}_{\mathrm{u}} / \sigma_{\mathrm{v}}^{\prime}\right)_{\mathrm{NC}}=4.2\right)$ due to the additional effective stress created by the maintained load $\left(\sigma_{\mathrm{v}, \text { eqm }}^{\prime}-\sigma_{\mathrm{v} 0}^{\prime}\right)$.

Overall, the stress paths show that the framework can capture a range of effects that lie behind the observed changes in soil strength and anchor capacity. For example, the level of pore pressure generation depends on the current pore pressure and the loading amplitude, which varies due to the level of anchor load as well as the position relative to the anchor. Also, the progressive consolidation, both during cycles and under maintained load, is illustrated, alongside the resulting changes in anchor capacity.

\section{CONCLUSIONS}

Plate anchors offer an efficient solution for mooring floating facilities. This paper describes a set of centrifuge experiments that illustrate how the capacity of a plate anchor in soft clay increases due to combinations of maintained and cyclic load. The tests show a 50\% gain in capacity after full consolidation under a maintained load of $50 \%$ of the monotonic undrained capacity. Also, 1080 cycles of one-way undrained cyclic loading over a much shorter period give a similar gain. Combinations of maintained and cyclic loading lead to even higher capacity increases, to $\sim 2.5$ times the initial value.

These results are replicated by simulations using the Zhou et al. (2019a) effective stress framework. This approach calculates changes in soil strength due to undrained shearing and consolidation and provides insights into the underlying stress paths within the loaded soil. Many of the framework parameters are derived from full-flow penetrometer tests, so there is the potential to bridge from in situ tests to plate anchor design calculations. The prediction approach outlined here is an effective means of establishing the magnitude and time scale of the capacity changes for particular combinations of anchor geometry, loading and seabed properties.

In summary, this paper indicates that a less conservative basis for plate anchor design may be 
Improvements in plate anchor capacity due to cyclic and maintained loads combined with consolidation

591

592

593

594

595

596

597

598

599

600

601

602

603

604

605

606

607

608

warranted, particularly if loading events are predictable - which is the case, for example, with offloading events for a taut moored floater. Further evidence for more general loading conditions (including an inclined plate and inclined loading) would provide wider validation in this regard. The model shown in this paper can be used to determine how gains in strength raise the reliability of the system, allowing resistance factors to be adjusted accordingly.

The model can also be a 'digital twin' of an anchor, since it can capture the changing capacity in response to any arbitrary loading sequence that the anchor is subjected to. In this way, the model could form part of an asset management system to monitor the integrity of the anchor and its ability to sustain additional loads as a result of revised design conditions or life extension requirements.

\section{ACKNOWLEDGEMENTS}

The first author acknowledges his research studentship support from the ARC Industrial Transformation Research Hub for Offshore Floating Facilities and the University of Western Australia. This work was supported by the ARC Industrial Transformation Research Hub for Offshore Floating Facilities which is funded by the Australia Research Council, Woodside Energy, Shell, Bureau Veritas and Lloyds Register (Grant No. IH140100012). The third author acknowledges the support of the Shell Chair in Offshore Engineering at UWA.

\section{NOTATION}

$\begin{array}{cl}b & \text { peak strength parameter, } k_{\Phi}(\hat{z})=\operatorname{OCR}(\hat{z})^{\mathrm{b}} \\ C_{\mathrm{V}} & \text { coefficient of consolidation } \\ C_{\mathrm{h}} & \text { coefficient of horizontal consolidation } \\ C_{\mathrm{op}} & \text { operative coefficient of consolidation } \\ d & \text { diameter of T-bar penetrometer } \\ D_{\mathrm{a}} & \text { diameter of circular plate anchor } \\ D_{\mathrm{a}} & \text { diameter of piezofoundation } \\ C & \text { elastic shear modulus } \\ I_{\mathrm{r}} & \text { rigidity index } \\ I_{\sigma} & \text { Boussinesq influence factor } \\ k & \text { soil strength gradient }\end{array}$




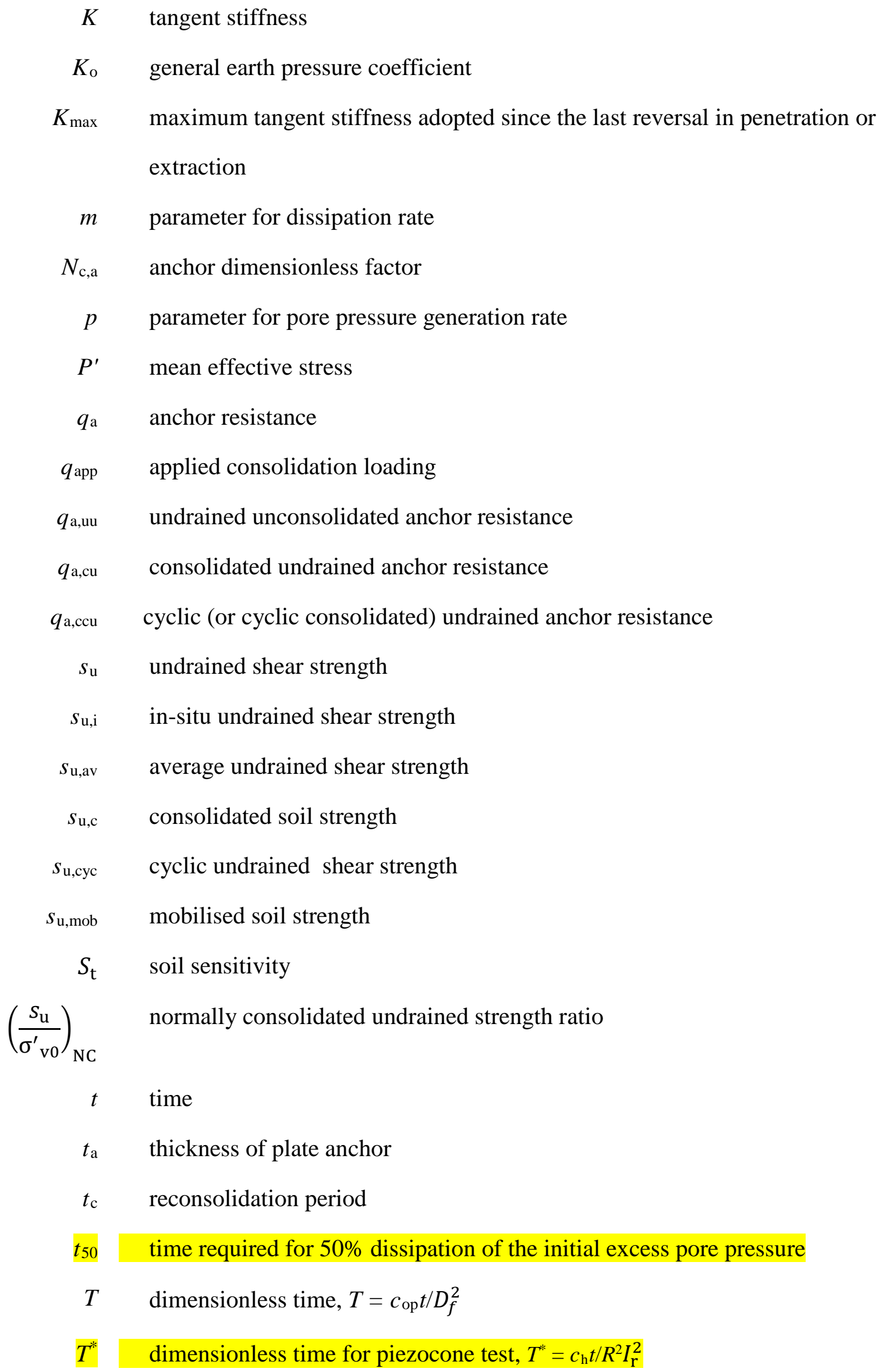


$T_{50}$ dimensionless time required for $50 \%$ dissipation of the initial excess pore pressure

$u_{\mathrm{e}} \quad$ excess pore pressure

$u_{\mathrm{e}, \mathrm{r}} \quad$ remaining potential excess pore pressure

$u_{\mathrm{e}, \max } \quad$ maximum excess pore pressure

$v_{\mathrm{s}} \quad$ strength influence function

$v \quad$ specific volume

$v_{\mathrm{d}} \quad$ velocity of penetrometer or plate anchor

$v_{\mathrm{i}} \quad$ initial specific volume

$x \quad$ horizontal displacement

z $\quad$ soil depth

$\hat{z} \quad$ normalised soil depth, $z / D$

$Z_{\mathrm{m}} \quad$ depth of center of plate anchor below soil surface

$\hat{Z}_{\mathrm{m}} \quad$ normalised depth, $Z_{\mathrm{m}} / D$

$\alpha \quad$ strength influence zone extent

$\beta \quad$ strain influence zone extent

$\lambda$ gradient of the normal consolidation line (NCL)

$\kappa \quad$ gradient of the unload-reload line (URL)

$\Phi \quad$ lumped strength parameter

$\sigma_{\mathrm{v}}^{\prime} \quad$ vertical effective stress

$\sigma_{\mathrm{v}, \mathrm{eqm}}^{\prime} \quad$ equilibrium vertical effective stress

$\sigma_{\mathrm{v}, \mathrm{NCL}} \quad$ vertical effective stress at NCL

$\sigma_{\mathrm{V}, \mathrm{RSL}}^{\prime} \quad$ vertical effective stress at RSL

$\sigma_{\mathrm{v} 0}^{\prime} \quad$ initial geostatic vertical effective stress

$\varepsilon \quad$ cumulative (absolute) shear strain

$\varepsilon_{98} \quad$ cumulative (absolute) shear strain required for a degree of remoulding equal to $98 \%$

$\mu \quad$ strain influence distribution function 
Improvements in plate anchor capacity due to cyclic and maintained loads combined with consolidation

Z. Zhou/C. D. O’Loughlin/D. J. White/S. A. Stanier

$\Gamma_{\mathrm{NCL}} \quad$ specific volume, $v, \sigma_{\mathrm{v}}^{\prime}=1 \mathrm{kPa}$ on the NCL

$\zeta \quad$ nonlinear tangent stiffness parameter

$\gamma^{\prime} \quad$ soil effective unit weight

609

610

611 
Improvements in plate anchor capacity due to cyclic and maintained loads combined with consolidation

\section{REFERENCES}

613

614

615

616

617

618

619

620

621

622

623

624

625

626

627

628

629

630

631

632

633

634

635

636

637

638

639

640

Andersen, K.H. (2015). Cyclic soil parameters for offshore foundation design. In Frontiers in Offshore Geotechnics-ISFOG III (Ed. Meyer, V.), 3-82, Oslo, Norway, Taylor \& Francis Group, London.

Andersen, K.H., Kleven, A. \& Heien, D. (1988). Cyclic soil data for design of gravity structures. ASCE, Journal of Geotechnical engineering. 114(5), 517-539.

Aubeny, C. (2018). Geomechanics of Marine Anchors. Boca Raton: CRC Press, https://doi.org/10.4324/9781351237376

Blake, A. and O’Loughlin, C.D. (2015). Installation of dynamically embedded plate anchors as assessed through field tests. Canadian Geotechnical Journal. 52(9), 1270-1282.

Blake, A. P., O'Loughlin, C.D. and Gaudin, C. (2011). Setup following keying of plate anchors assessed through centrifuge tests in kaolin clay. Proceedings of the 2nd International Symposium on Frontiers in Offshore Geotechnics. The Netherlands: CRC Press/Balkema, 705-710.

Boussinesq, J. (1885). Application des potentiels à l'étude de l'équilibre et du mouvement des solides élastiques: mémoire suivi de notes étendues sur divers points de physique mathématique et d'analyse. Paris, France: Gauthier-Villars (in French).

Brown, R. P., Wong, P. C. and Audibert, J. M. (2010). SEPLA keying prediction method based on full-scale offshore tests. In Proceedings of the International Symposium on Frontiers in Offshore Geotechnics II, Perth, Australia, 717-722

Cassidy, M. J., Gaudin, C., Randolph, M. F., Wong, P. C., Wang, D. and Tian, Y. (2012). A plasticity model to assess the keying of plate anchors. Géotechnique, 62(9), 825-836.

Chang, K., Hossain, M. S., Kim, Y. H. and Wang, D. (2017). Cyclic capacity and diving potential of novel fish anchor in calcareous silt. ASCE Journal of Geotechnical and Geoenvironmental Engineering. Under review.

Chatterjee, S., White, D. J. and Randolph, M. F. (2013). Coupled consolidation analysis of pipe-soil interactions. Canadian Geotechnical Journal. 50(6), 609-619.

Chow, S.H., O’Loughlin, C.D., Zhou, Z., White, D.J. and Randolph, M.F. (2019). Penetrometer testing in a calcareous silt to explore changes in soil strength. Géotechnique. Under 
Improvements in plate anchor capacity due to cyclic and maintained loads combined with consolidation review.

Chung S.F. and Randolph (2004). Penetration resistance in soft clay for different shaped penetrometers. Proc. ISC-2 on Geotechnical and Geophysical Site Characterization. 671-677.

Cocjin, M.L., Gourvenec, S.M., White, D.J. and Randolph, M.F. (2014). Tolerably mobile subsea foundations-observations of performance. Géotechnique, 64(11), 895-909.

Colliat, J. L., Dendani, H., Puech, A. and Nauroy, J. F. (2010). Gulf of Guinea deepwater sediments: Geotechnical properties, design issues and installation experiences. In Proceedings of the International Symposium on Frontiers in Offshore Geotechnics II, Perth, Australia, 59-86.

Colreavy, C., O’Loughlin, C. D. and Randolph, M. F. (2016). Experience with a dual pore pressure element piezoball. International Journal of Physical Modelling in Geotechnics, 16(3), 101118.

Dahlberg, R. and Strøm, P.J. (1999), Unique onshore tests of deepwater drag-in plate anchors, Proc. Offshore Technology Conference, Paper OTC 10989. Houston.

656

657

658

660

661

662

663

664

665

666

Heyerdahl, H. and Eklund, T. (2001), Testing of plate anchors. Proc. Offshore Technology Conference, Paper OTC 13273. Houston.

Gaudin, C., O'Loughlin, C.D., Randolph, M. and Lowmass, A. C. (2006). Influence of the installation process on the performance of suction embedded plate anchors. Géotechnique. 56(6), 381-391.

Gourvenec, S. and Randolph, M. F. (2010). Consolidation beneath circular skirted foundations, International Journal for Geomechanics, 10(1), 22-29.

Grieves M. and Vickers J. (2017). Digital Twin: Mitigating Unpredictable, Undesirable Emergent Behavior in Complex Systems. In: Kahlen FJ., Flumerfelt S., Alves A. (eds) Transdisciplinary Perspectives on Complex Systems. Springer, Cham, 85-113.

Han, C. (2016). Performance of plate anchors under sustained loading. PhD thesis. The University of Western Australia.

Hodder, M.S., Cassidy, M.J. and Barrett, D. (2008). Undrained response of shallow pipelines subjected to combined loading. In Proc. $2^{\text {nd }}$ British Geotechnical Association 
Improvements in plate anchor capacity due to cyclic and maintained loads combined with consolidation

International Conference on Foundation, Dundee, Scotland.

House, A., Olivera, J. R. M. S. and Randolph, M. F. (2001). Evaluating the coefficient of consolidation using penetration tests. International Journal of Physical Modelling in Geotechnics, 3, 17-25.

Liu, J., Tan, M. and Hu Y. (2018). New analytical formulas to estimate the pullout capacity factor for rectangular plate anchors in NC clay. Applied Ocean Research, 75, 234-247.

Mahmoodzadeh, H., Wang, D. and Randolph, M.F., 2015. Interpretation of piezoball dissipation testing in clay. Géotechnique, 65(10), 831-842.

Martin, C. M. and Randolph, M. F. (2001). Application of the lower bound and the upper bound theorems of plasticity to collapse of circular foundations. Proc. 10th Int. Conf. Comp. Methods Adv. Geol., Tucson, 2, 1417-1428.

Martin, C. M. and Randolph, M. (2006). Upper-bound analysis of lateral pile capacity in cohesive soil. Géotechnique, 56(2), 141-145.

Merifield, R. S., Lyamin, A. V., Sloan, S. W. and Yu, H. S. (2003). Three-dimensional lower bound solutions for stability of plate anchors in clay. J. Geotech. Geoenviron. Engng, ASCE, 129(3), 243-253.

O'Loughlin, C.D., Blake, A., Richardson, M. D., Randolph, M. and Gaudin, C. (2014). Installation and capacity of dynamically embedded plate anchors as assessed through centrifuge tests, Ocean Engineering, 88, 204-213.

O'Loughlin, C. D., White, D. J. and Stanier, S. A. (2015). Novel Anchoring Solutions for FLNG - Opportunities Driven by Scale. Proceedings of the 2015 Offshore Technology Conference. Houston, Vol. 6. 4314-4345.

O'Loughlin, C. D., Blake, A. P. and Gaudin, C. (2016). Towards a simple design procedure for dynamically embedded plate anchors. Géotechnique, 66(9), 741-753.

O'Loughlin, C. D., White, D. J. and Stanier, S. A. (2017). Plate anchors for mooring floating facilities - a view towards unlocking cost and risk benefits. Offshore Site Investigation and Geotechnics 2017 Conference Proceedings. United Kingdom, Vol. 2. 978-986.

O'Loughlin, C.D., Neubecker, S. and Gaudin, C. (2018). Anchoring Systems: Anchor Types, Installation, and Design. In Encyclopedia of Maritime and Offshore Engineering (eds J. 
Improvements in plate anchor capacity due to cyclic and maintained loads combined with consolidation Carlton, P. Jukes and Y. S. Choo). doi:10.1002/9781118476406.emoe534.

700

701

702

703

704

705

706

707

708

709

710

711

712

713

714

715

716

717

718

719

720

721

722

723

724

Poulos, H. G. and Davis, E. H. (1974). Elastic solution for soil and rock mechanics. John Wiley \& Sons. USA.

Randolph, M. F., Jewell, R. J., Stone, K. J. and Brown, T. A. (1991). Establishing a new centrifuge facility. In Proceedings of the international conference on centrifuge modelling, Centrifuge '91, Rotterdam, the Netherlands, 3-9.

Randolph, M.F. and Hope, S.N. (2004). Effect of cone velocity on cone resistance and excess pore pressure. Proc. Conf. on Engineering Practice and Performance of Soft Deposits, Osaka, 147-152.

Randolph, M. F., Low, H. E. and Zhou, H. (2007). In situ testing for design of pipeline and anchoring systems. Proceedings of the $6^{\text {th }}$ International Conference on Offshore Site Investigation and Geotechnics: Confronting New Challenges and Sharing Knowledge London, UK., 251-262.

Renzi, D., Maniar, D., McNeill, S. and Del Vecchio, C. (2017). Developing a digital twin for floating production systems integrity management. Proc. Offshore Technology Conference (OTC Brasil), Paper No. OTC-28012-MS, doi:10.4043/28012-MS.

Sharma, P., Hamedifar, H., Brown, A., and Green, R. (2017). The dawn of the new age of the industrial internet and how it can radically transform the offshore oil and gas industry. Proc. Offshore Technology Conference, Paper No. OTC-27638-MS, doi:10.4043/27638MS

Stanier S.A. and White D.J. (2019). Enhancement of bearing capacity from consolidation: due to changing strength or failure mechanism? Géotechnique, 69(2), 166-173

Stewart, D. P. and Randolph, M. F. (1991). A new site investigation tool for the centrifuge. In Proceedings of the International Conference on Centrifuge Modelling, Centrifuge '91, Boulder, Colorado, USA, 531-538.

Stewart, D.P. and Randolph, M.F. (1994). T-Bar penetration testing in soft clay. Journal of Geotechnical Engineering, ASCE, 120(12), 2230-2235.

Teh, C. I. and Houlsby, G. T. (1991). An analytical study of the cone penetration test in clay. Géotechnique, 41(1), 17-34. 
Improvements in plate anchor capacity due to cyclic and maintained loads combined with consolidation

Vryhof anchors (2006). Vryhof anchor manual 2006. Vryhof anchors BV. The Netherlands.

Wang, D., Hu, Y. and Randolph, M. (2010). Three-dimensional large deformation finiteelement analysis of plate anchors in uniform clay. Journal of Geotechnical and Geoenvironmental Engineering. 136(2), 355-365.

733

Wang, D., Gaudin, C. and Randolph, M. (2013). Large deformation finite element analysis investigating the performance of anchor keying flap. Ocean Engineering, 59, 107-116.

Wang, D. and O’Loughlin, C. D. (2014). Numerical study of pull-out capacities of dynamically embedded plate anchors. Canadian Geotechnical Journal, 51(11), 1263-1272.

White, D. J. and Hodder, M. (2010). A simple model for the effect on soil strength of episodes of remoulding and reconsolidation. Canadian Geotechnical Journal, 47(7), 821-857.

Wilde, B., Treu, H., and Fulton, T. (2001) Field testing of suction embedded plate anchors. Proc. $11^{\text {th }}$ ISOPE Conf., 2, 544-551.

Wong, P., Gaudin, C., Randolph, M., Cassidy, M. and Tian, Y. (2012). Performance of suction embedded plate anchors in permanent mooring applications. The Proceedings of The Twenty-second (2012) International Offshore and Polar Engineering Conference. USA. 640-645.

Yu, L., Liu, J., Kong, X.-J. and Hu, Y. (2011). Numerical study on plate anchor stability in clay. Géotechnique, 61(3), 235-246.

Zhou Z., White D. J. and O’Loughlin, C. D. (2019a). An effective stress framework for estimating penetration resistance accounting for changes in soil strength from maintained load, remoulding and reconsolidation. Géotechnique, 69(1), 57-71.

Zhou, Z., White, D.J. and O’Loughlin, C.D. (2019b). The changing strength of soft soils: Parallel penetrometer and foundation tests with cyclic loading and reconsolidation periods. Canadian Geotechnical Journal, under review. 


\section{FIGURE CAPTIONS}

756 Figure 1 Model anchor 31

Figure 2 Experimental arrangement at different stages: (a) cutting a slot for the anchor loading line; (b) before anchor installation; (c) after anchor installation; (d) in preparation for loading

760 Figure 3 T-bar test data: (a) undrained shear strength profiles; (b) soil strength variation factor during cyclic remoulding $(z=75 \mathrm{~mm})$

Figure 4 Undrained shear strength profiles in T-bar tests with load-controlled cycles: (a) TB_03 with 1080 cycles between 0.25 and $0.75 s_{u, i}$; (b) TB_04 with 1080 cycles between 0 and

Figure 5 Excess pore pressure response in piezocone dissipation tests .36

Figure 6 Excess pore pressure response in piezofoundation dissipation tests..... .36

Figure 8 Loading sequence for anchor tests: (a) Test 1; (b) Test 2; (c) Test 3; (4) Test 4 .....38

Figure 10 Increase in anchor resistance due to consolidation during (and following) maintained and cyclic loading

772 Figure 11 Maintained and cyclic loading sequence and the corresponding anchor displacement

773 response: (a) Test 1; (b) Test 2; (c) Test 3; (4) Test 4

774 Figure 12 Effective stress framework: (a) one-dimension horizontal row of soil elements for this study; (b) effective stress paths due to remoulding, cyclic loading, reconsolidation and maintained load

Figure 13 Comparison of experimental and simulated episodic cyclic T-bar: (a) depth profiles of undrained shear strength; (b) evolution of normalised soil strength, $s_{\mathrm{u}} / \mathrm{s}_{\mathrm{u}, \mathrm{i}}$, during and after cycles at the mid-depth of the cycles

780 Figure 14 Experimental and simulated anchor capacities: (a) Test 1; (b) Test 2; (c) Test 3; (d)

782 Figure 15 Effective stress paths: (a) at $z / D_{a}=0$ and 0.26 for Test 1 ; (b) at $z / D_{a}=0,0.46$ and 7831.2 for Test 2; (c) at $z / D_{\mathrm{a}}=0$ and 0.26 for Test 3; (d) at $z / D_{\mathrm{a}}=0$ and 0.26 for Test 4 ; (e) at $z / D_{\mathrm{a}}$ $784=0.26$ for an extended simulation of Test 4 (involving 200 episodes) .49 
Improvements in plate anchor capacity due to cyclic and maintained loads combined with consolidation Z. Zhou/C. D. O’Loughlin/D. J. White/S. A. Stanier

10. TABLE CAPTIONS

788 Table 1 Properties of calcareous silt (from Chow et al. 2019) .50

789 Table 2 Summary of anchor tests: loading sequences, test results and simulation results ......51

790 Table 3 Summary of framework parameters used in the simulation of the episodic cyclic T-bar

791 test....... .52 .53 
794

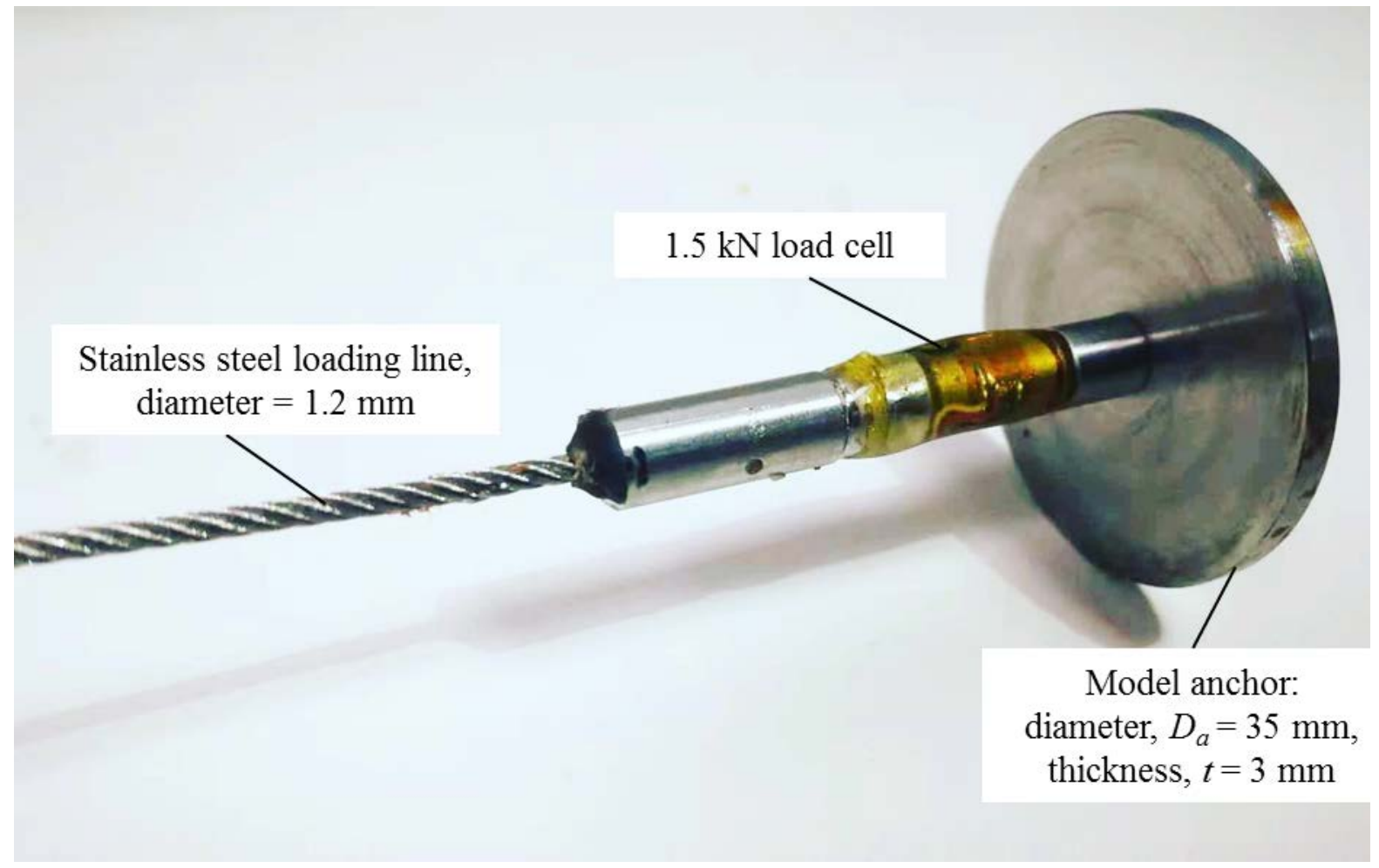

Figure 1 Model anchor 


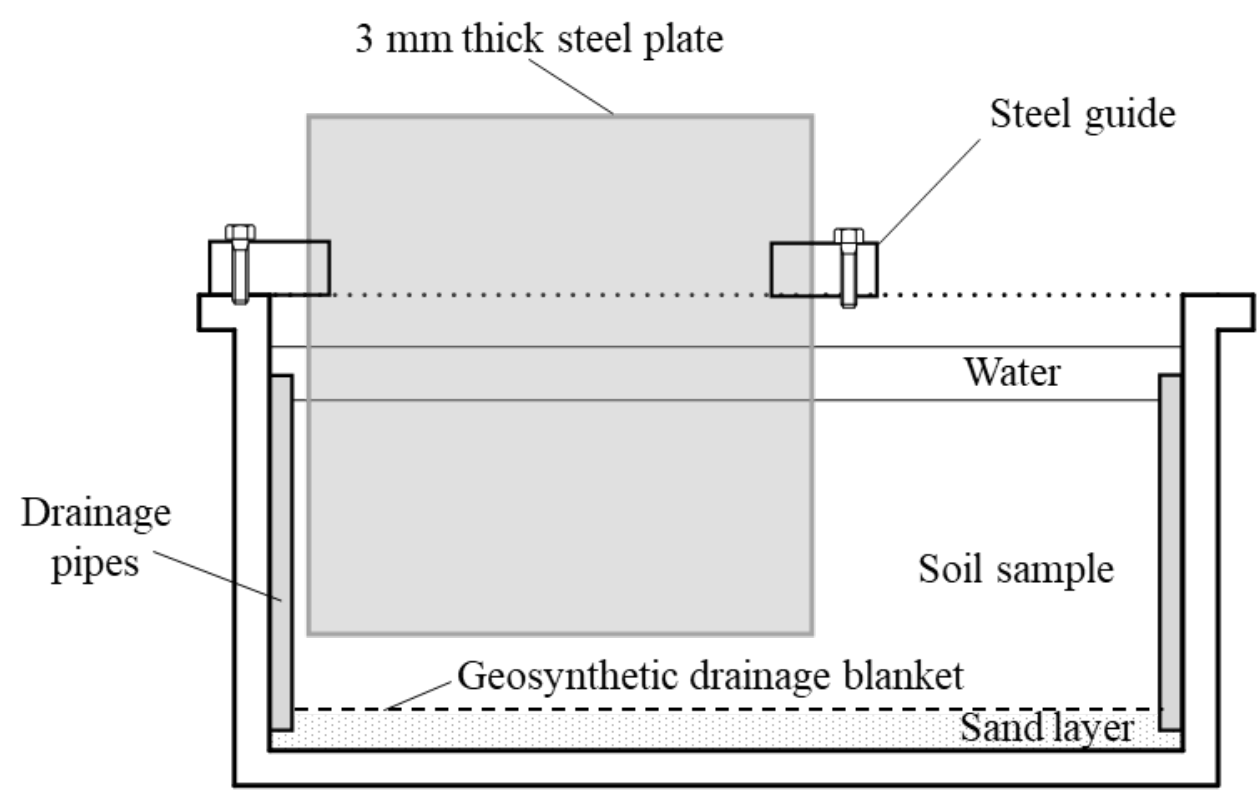

(a)

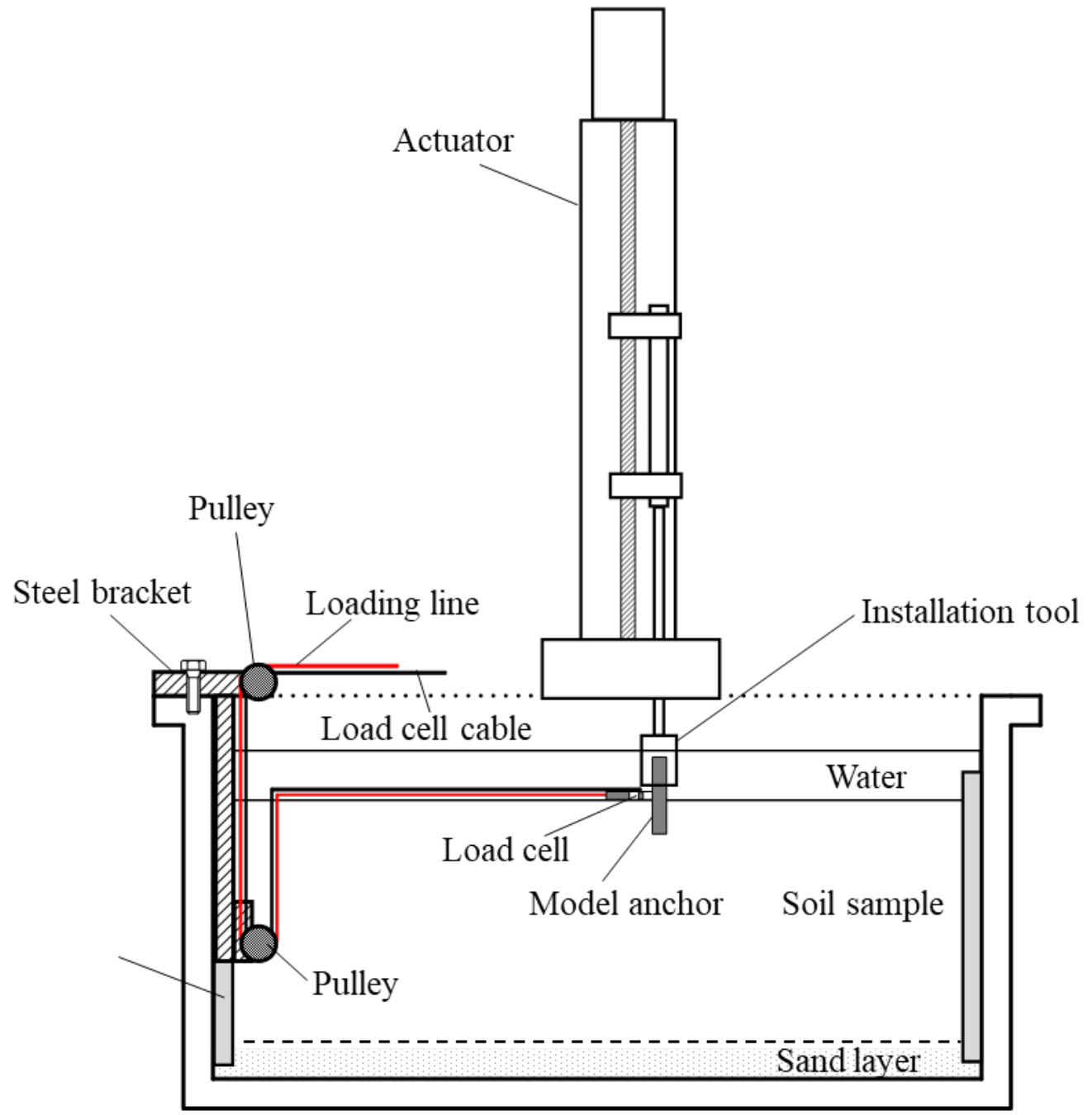

(b) 


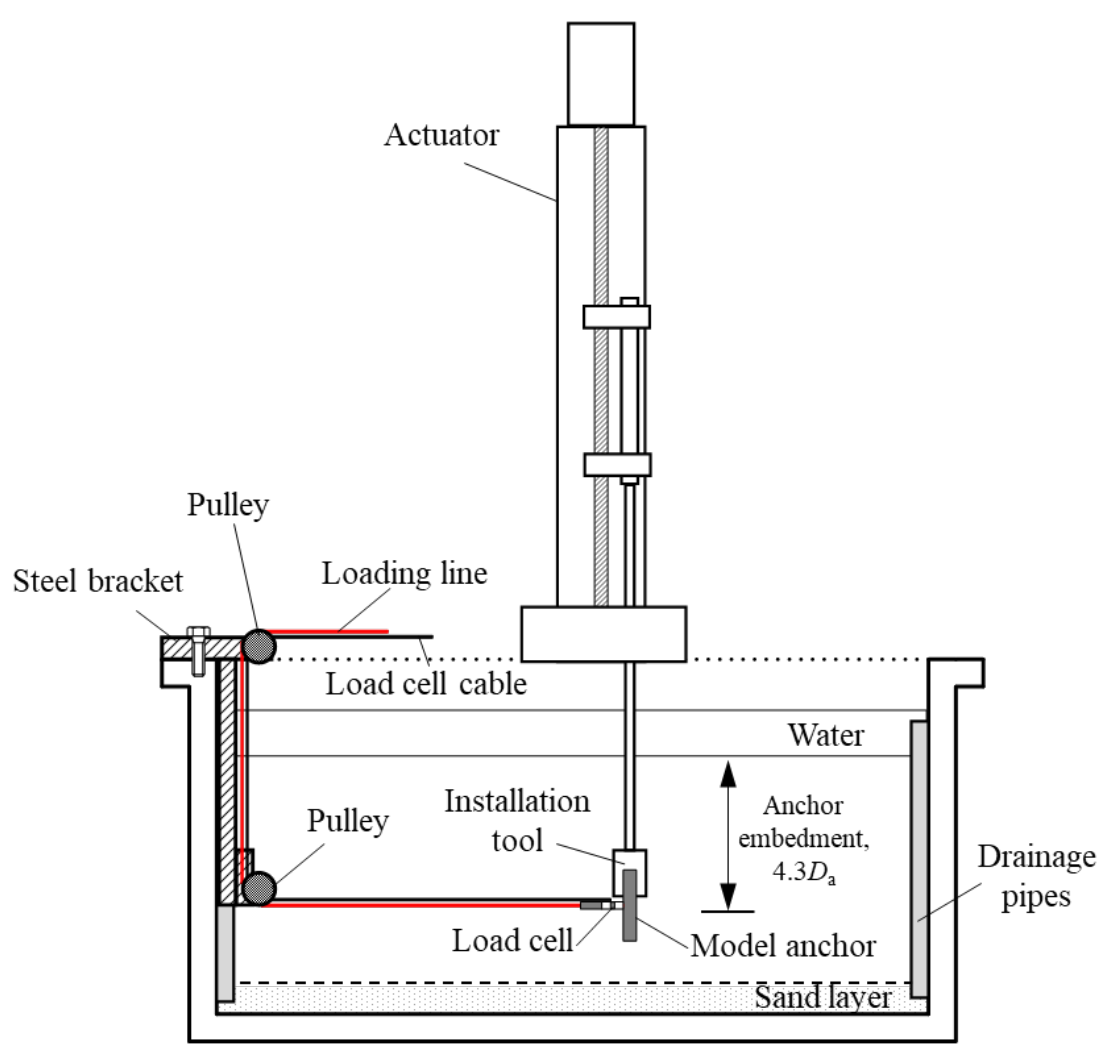

(c)

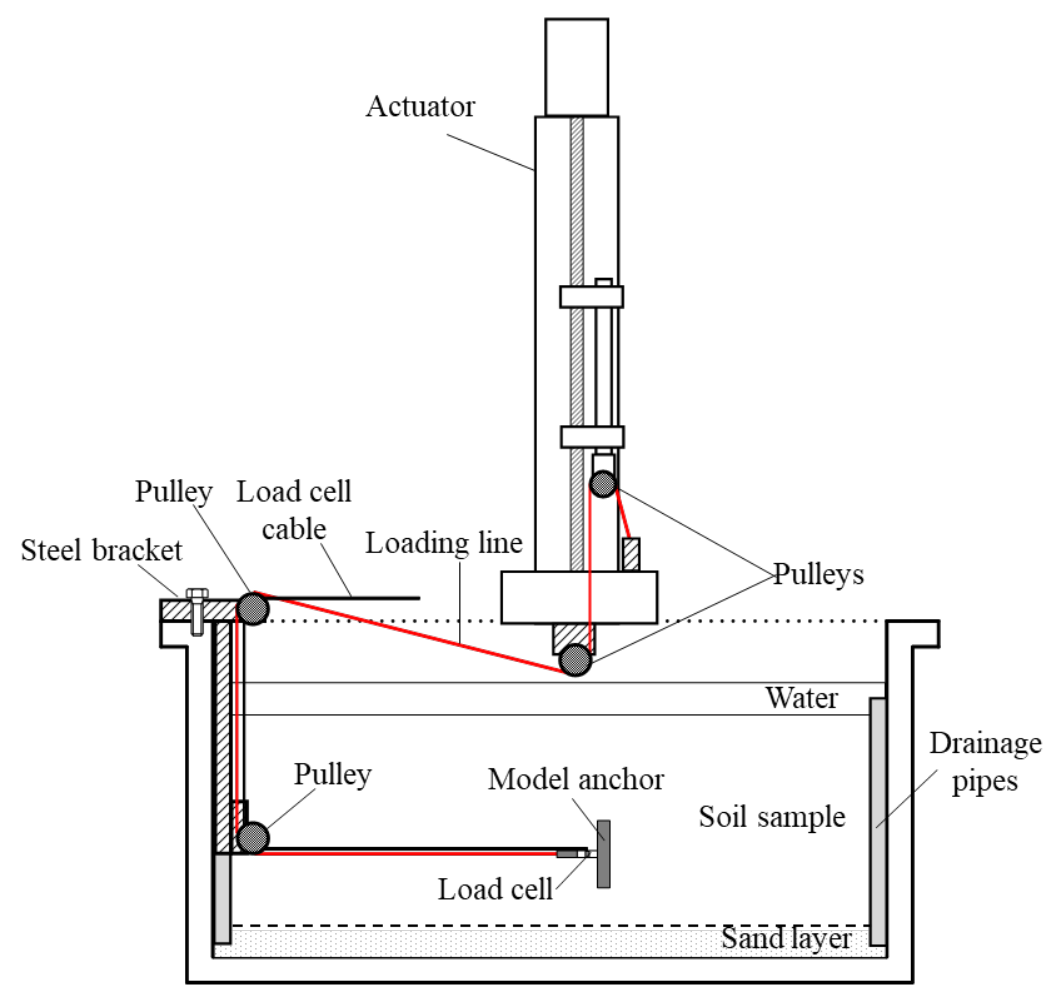

(d)

Figure 2 Experimental arrangement at different stages: (a) cutting a slot for the anchor loading line; (b) before anchor installation; (c) after anchor installation; (d) in preparation for loading 


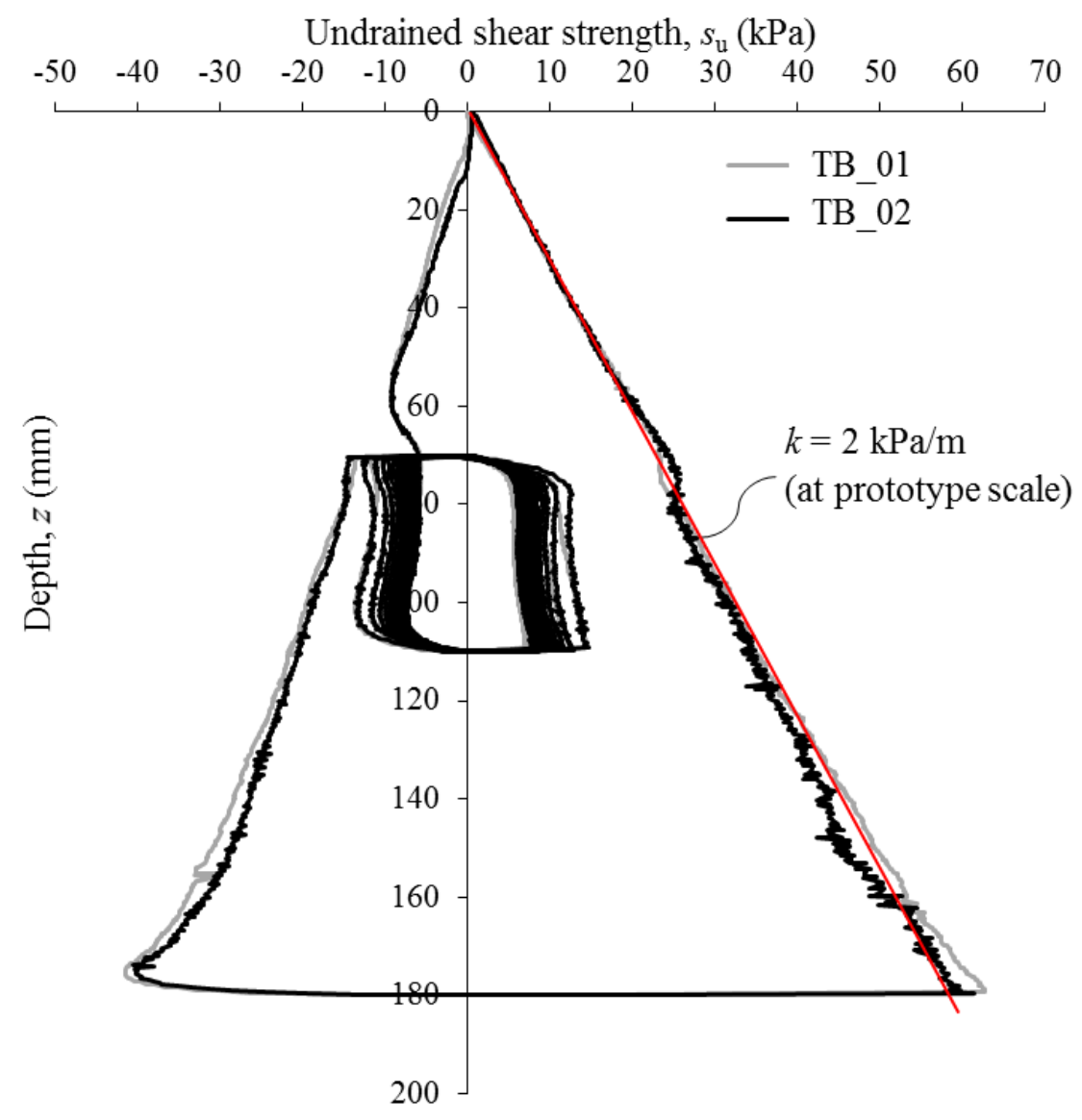

(a)

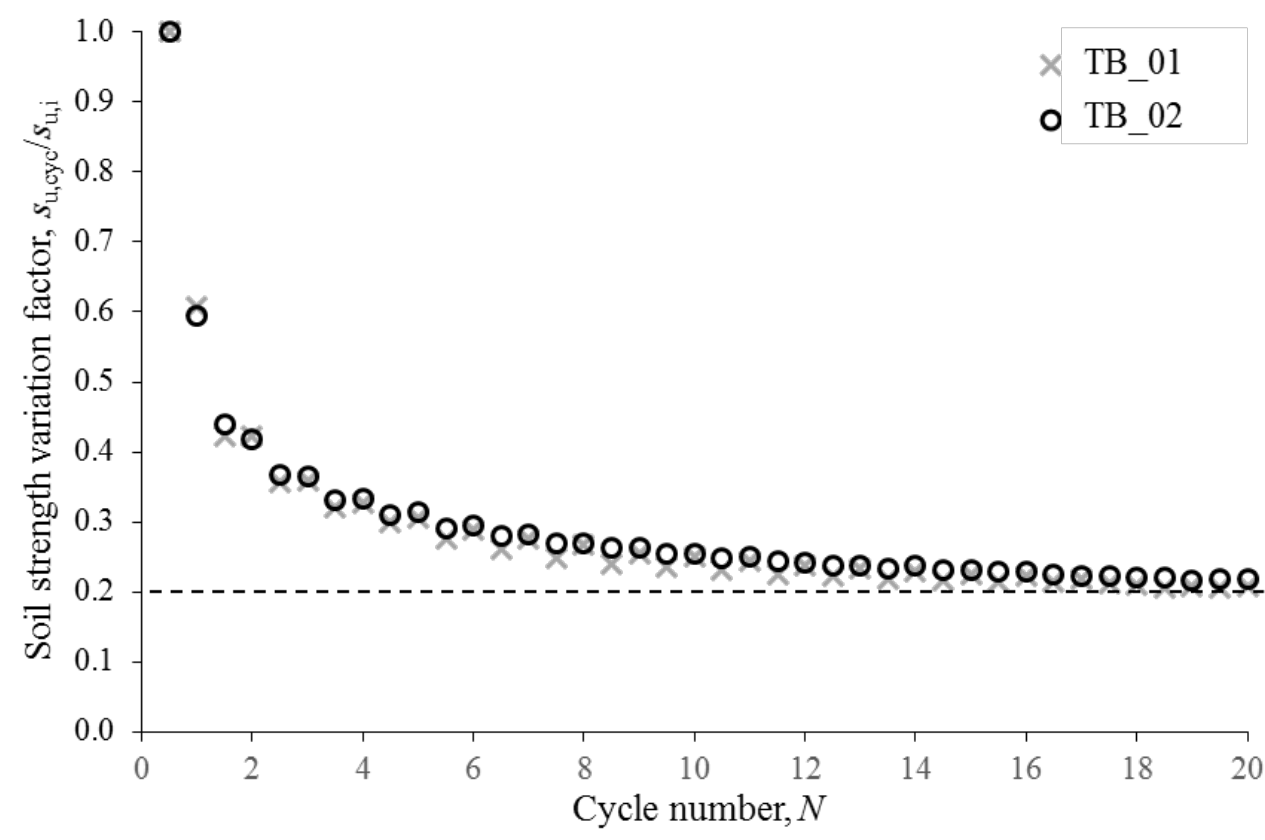

(b)

Figure 3 T-bar test data: (a) undrained shear strength profiles; (b) soil strength variation factor during cyclic remoulding $(z=75 \mathrm{~mm})$ 


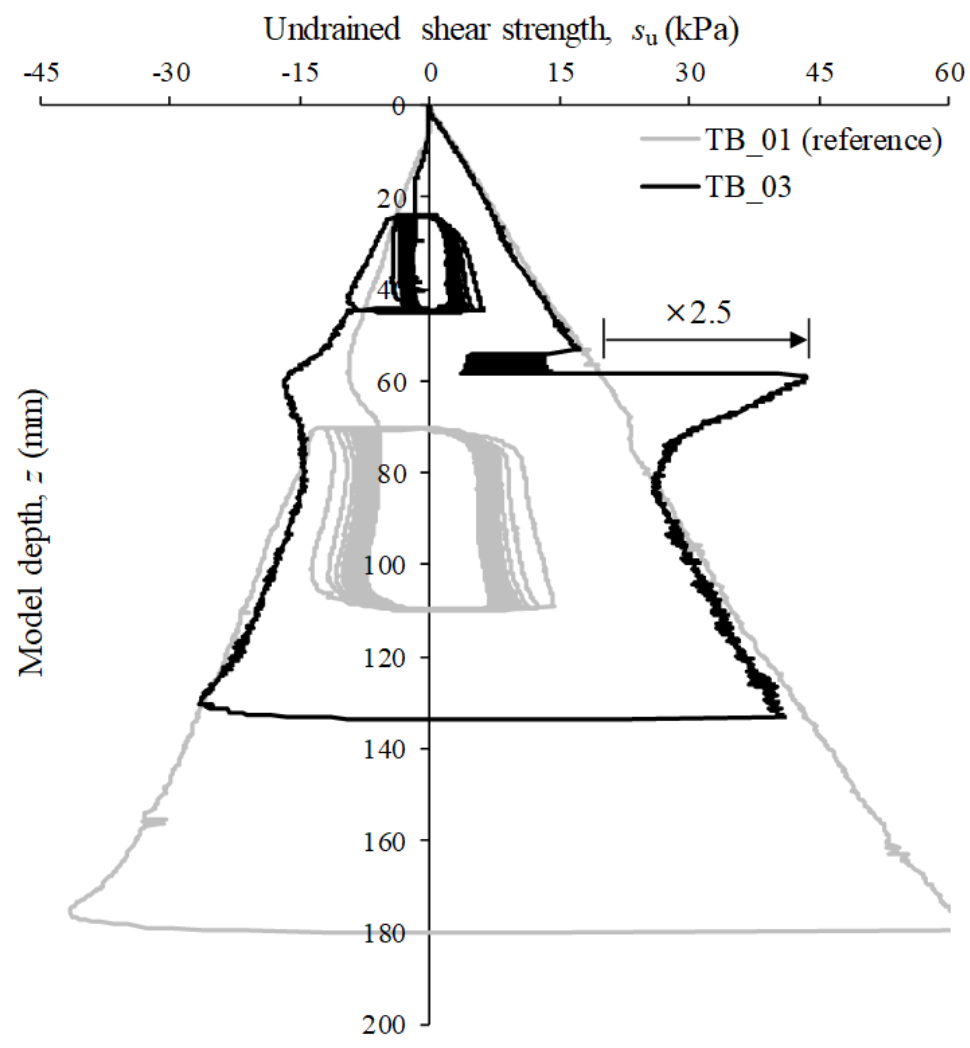

(a)

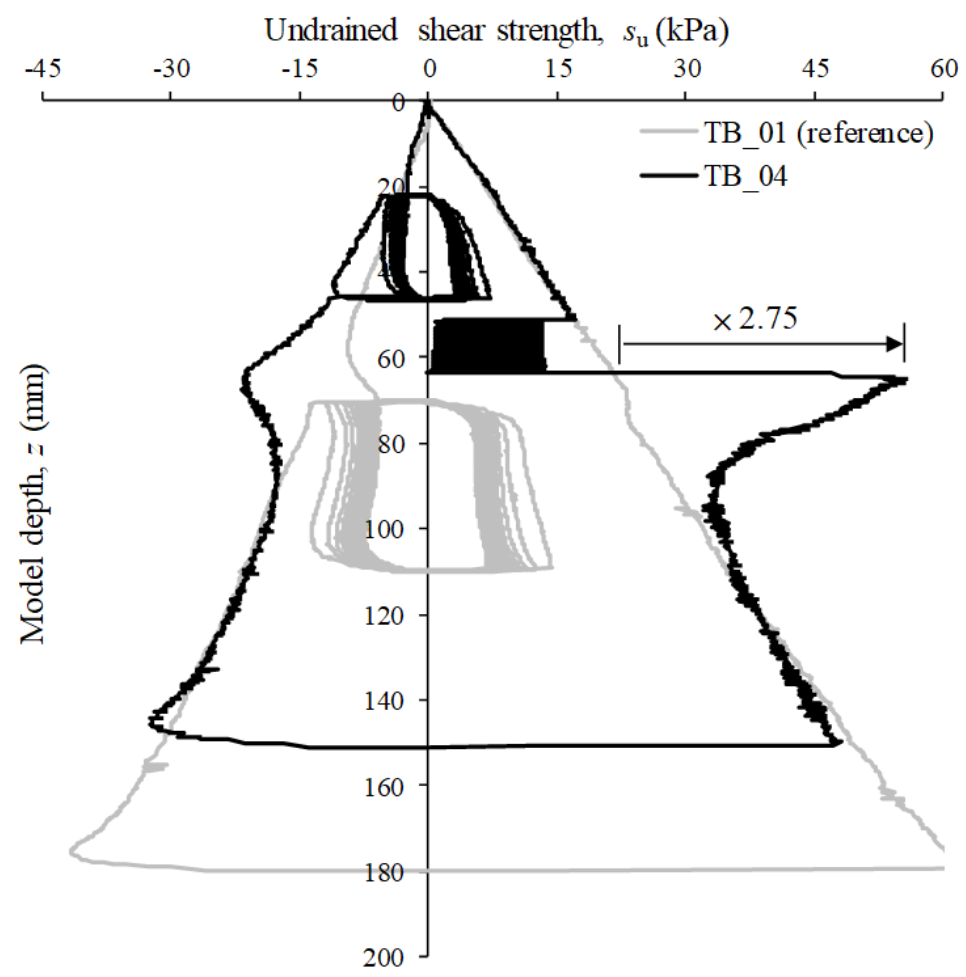

(b)

Figure 4 Undrained shear strength profiles in T-bar tests with load-controlled cycles: (a) TB_03 with 1080 cycles between 0.25 and $0.75 s_{u, i}$; (b) TB_04 with 1080 cycles between 0 and $0.75 s_{u, i}$ 
804

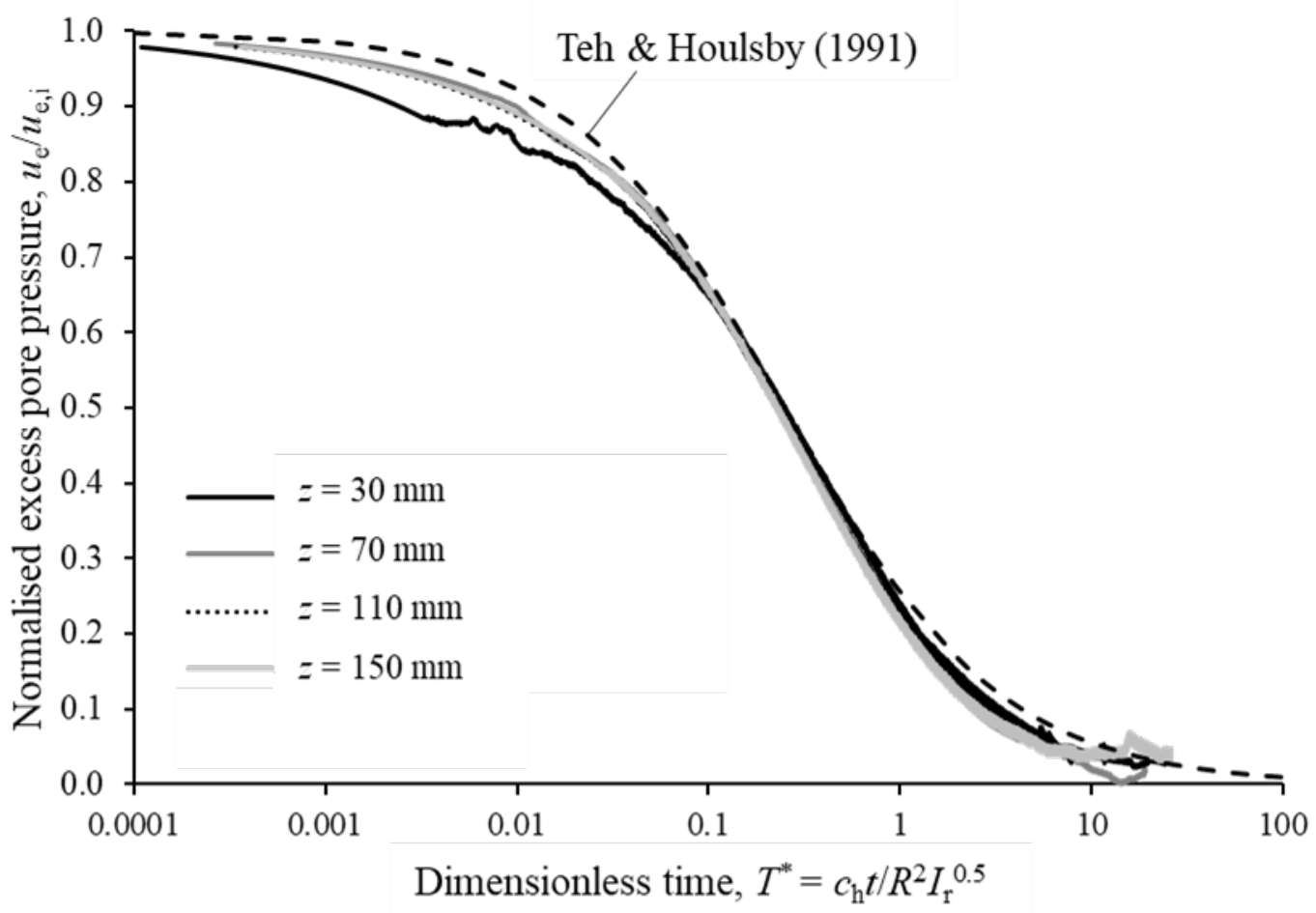

Figure 5 Excess pore pressure response in piezocone dissipation tests

805

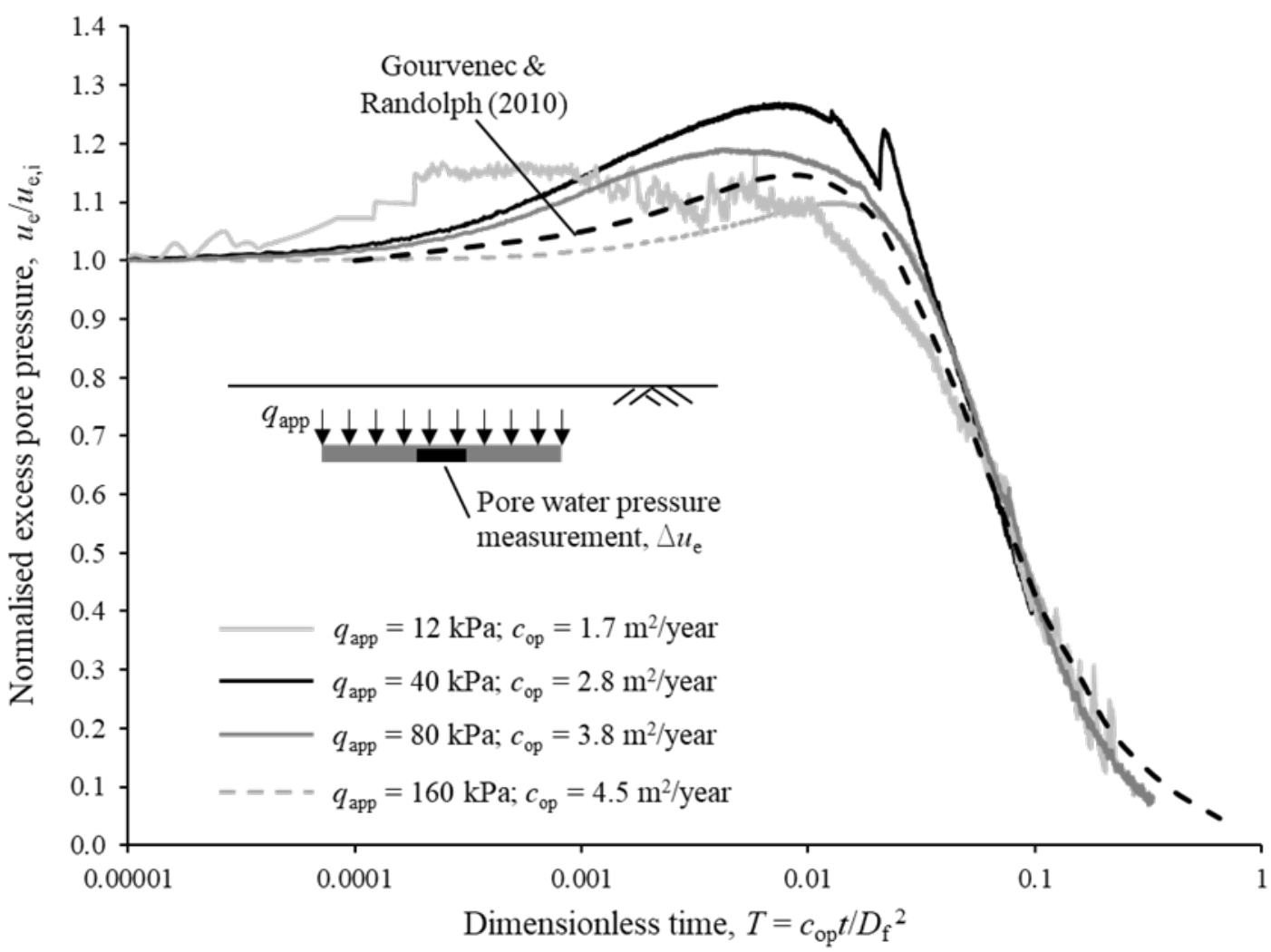

Figure 6 Excess pore pressure response in piezofoundation dissipation tests 
Improvements in plate anchor capacity due to cyclic and maintained loads combined with consolidation

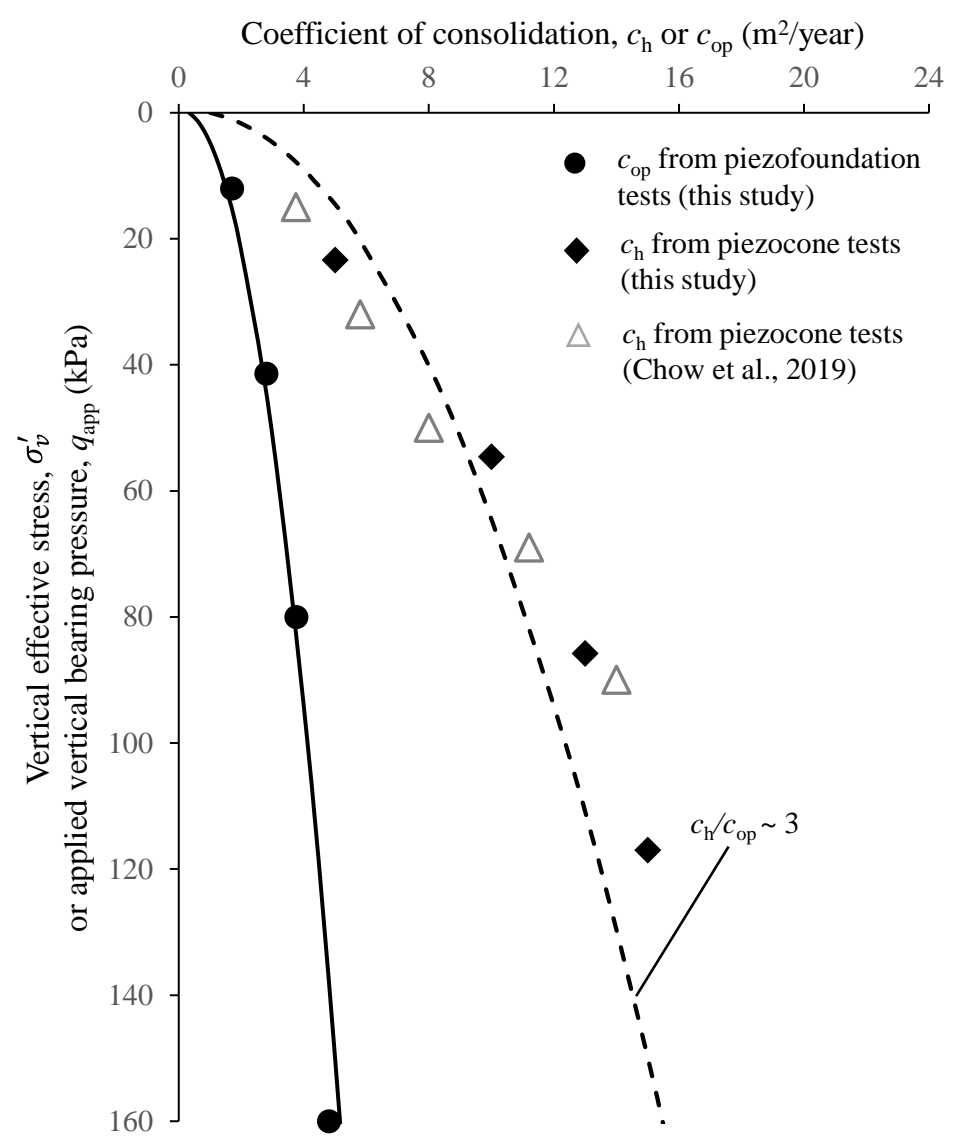

Figure 7 Coefficients of consolidation from piezocone and piezofoundation tests 


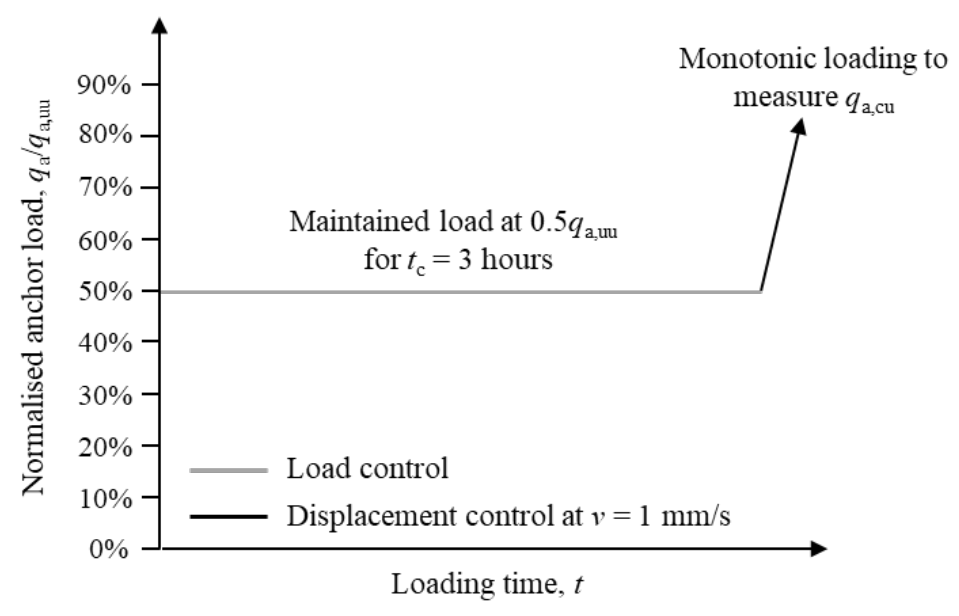

(a)

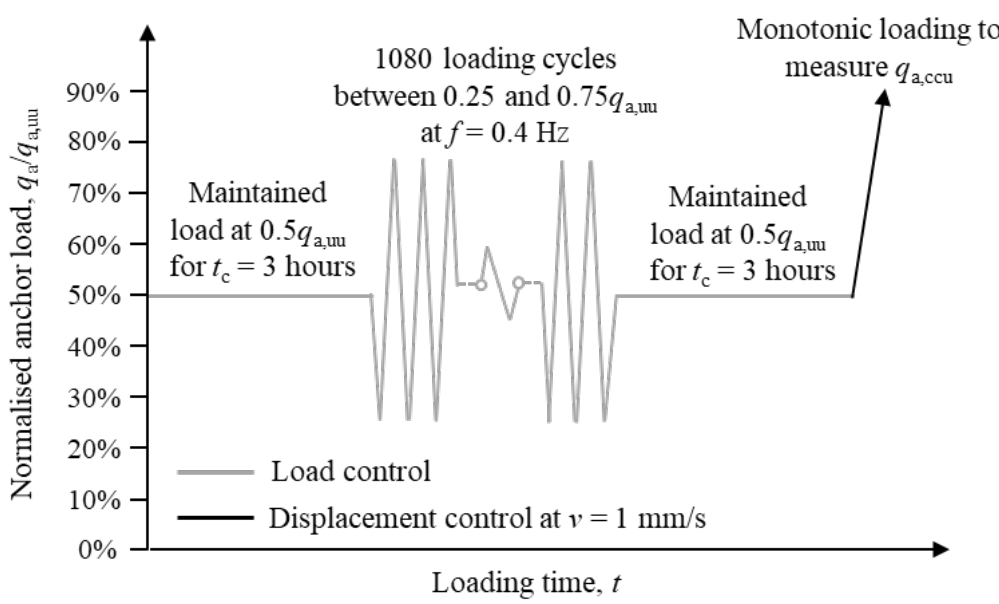

(c)

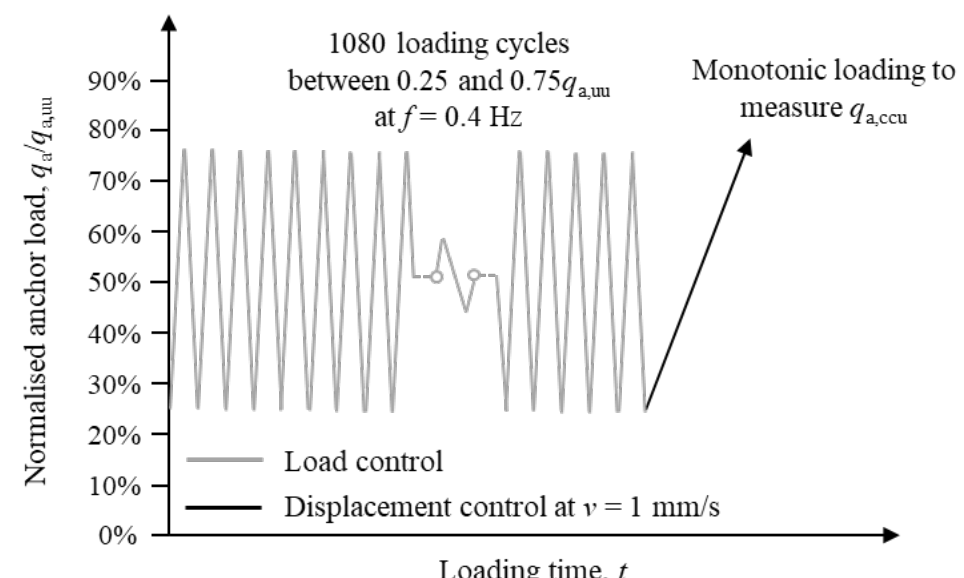

(b)

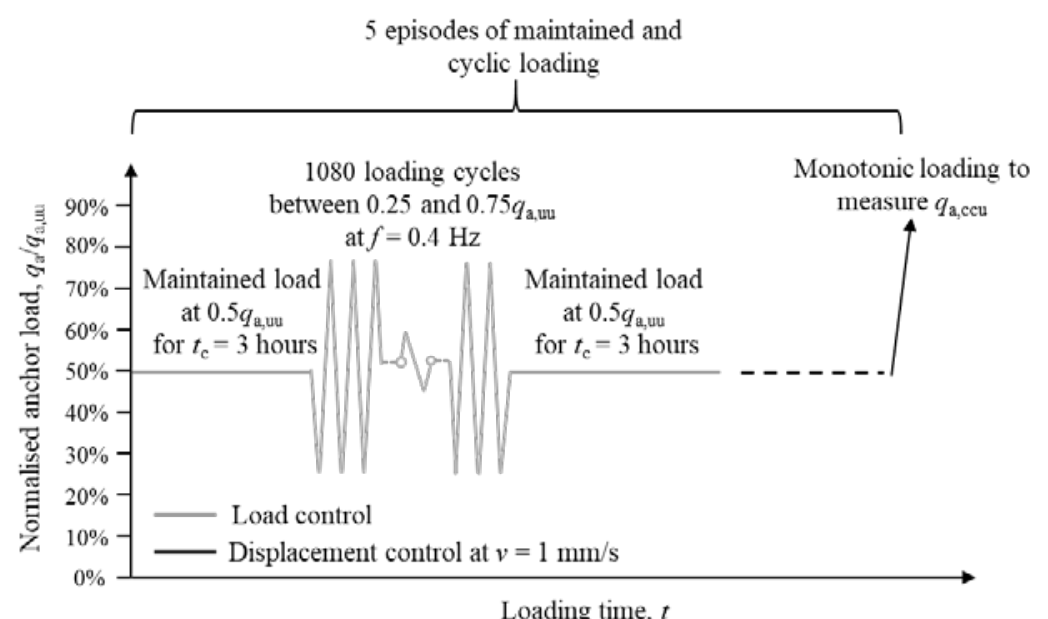

(d)

Figure 8 Loading sequence for anchor tests: (a) Test 1; (b) Test 2; (c) Test 3; (4) Test 4 
809

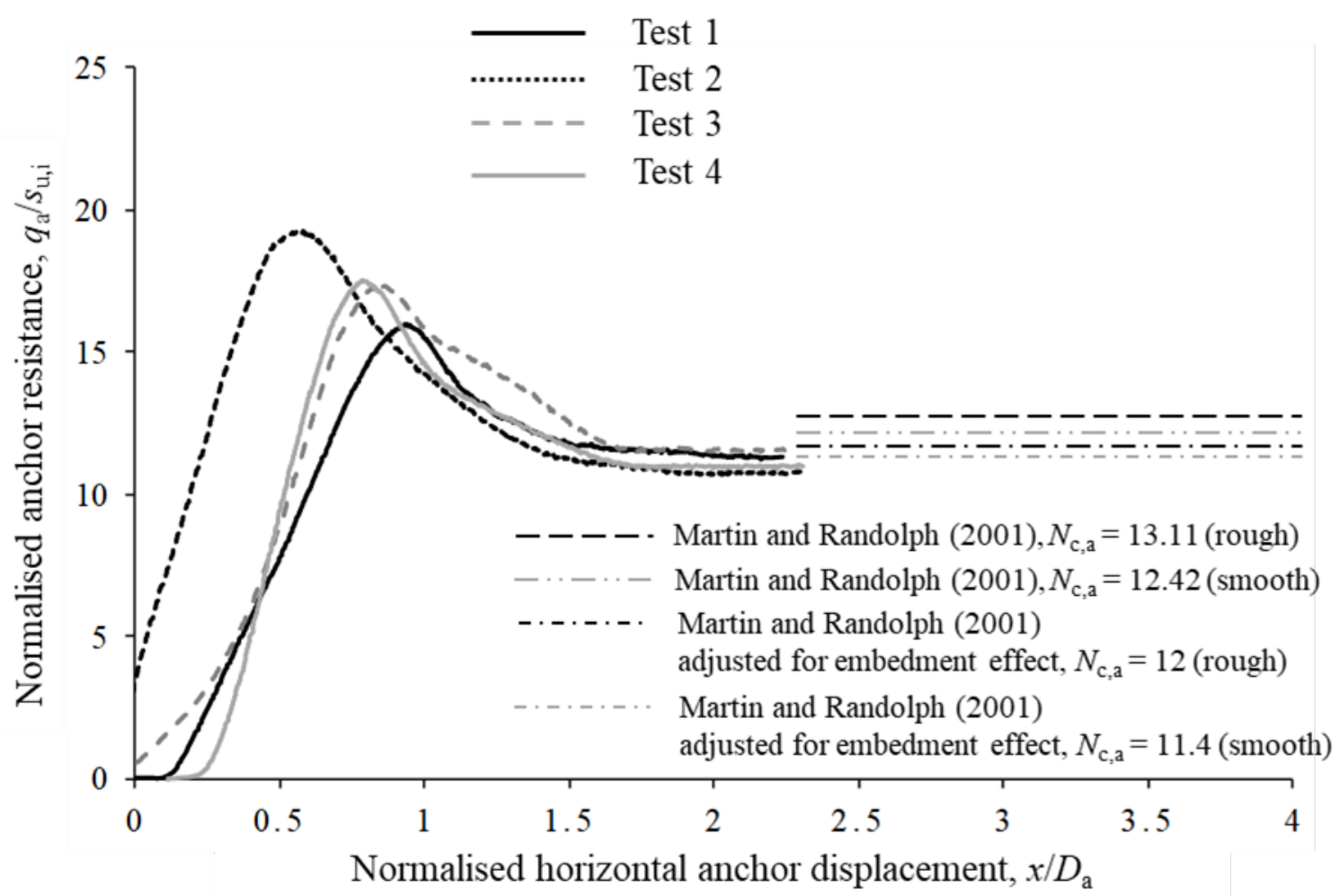

Figure 9 Anchor capacity response during the initial monotonic loading stage

810

811

812

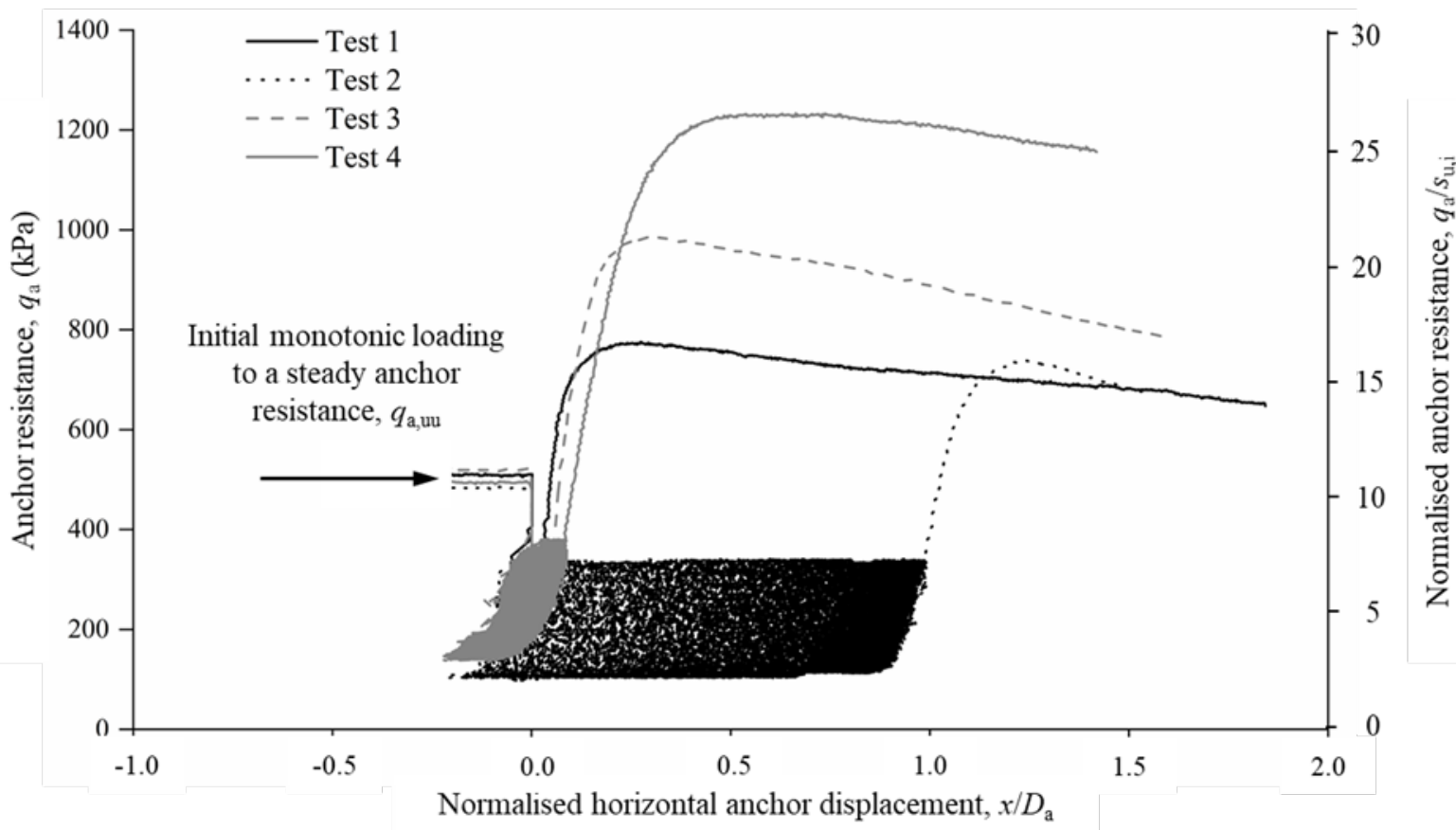

Figure 10 Increase in anchor resistance due to consolidation during (and following) maintained and cyclic loading 


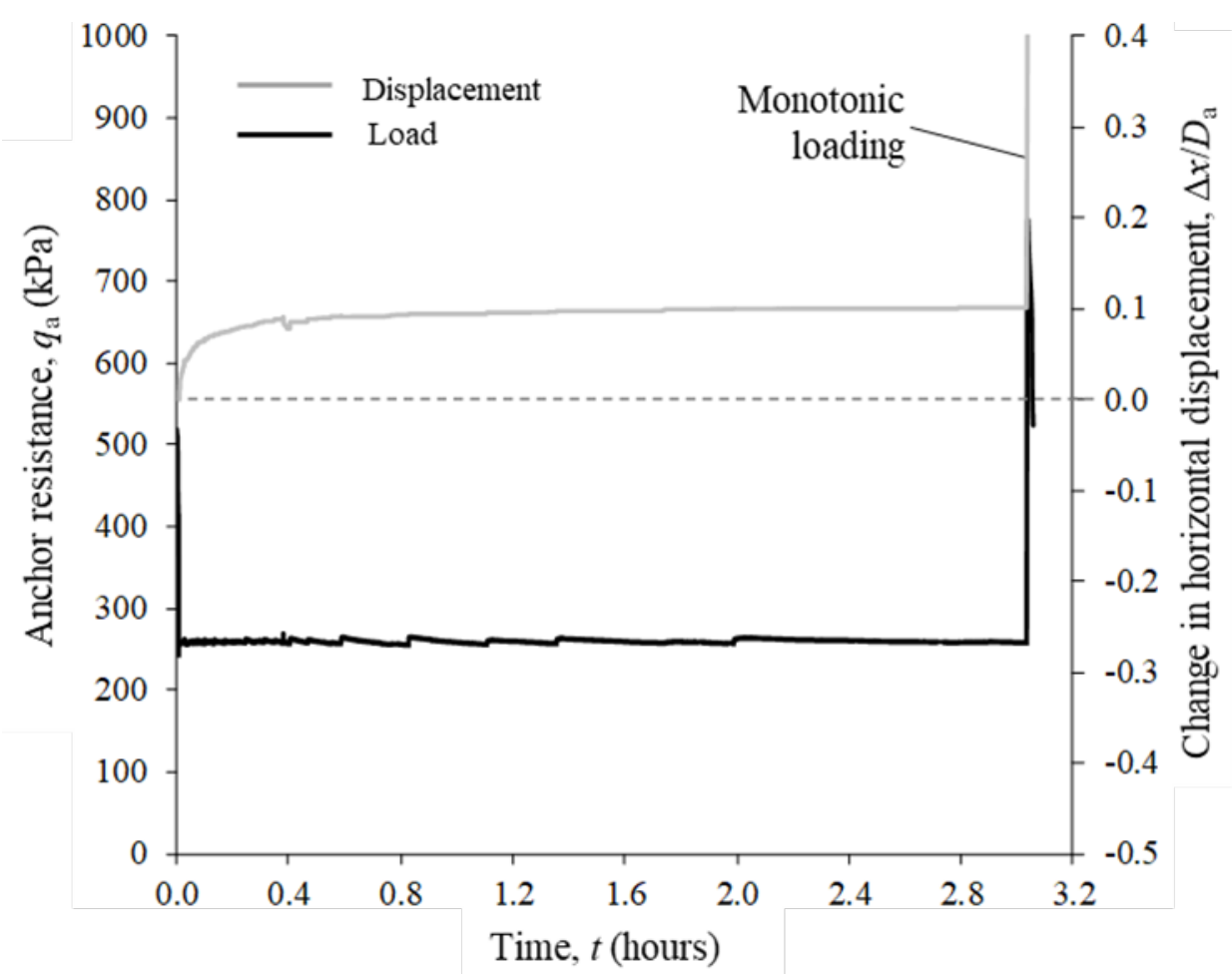

(a)

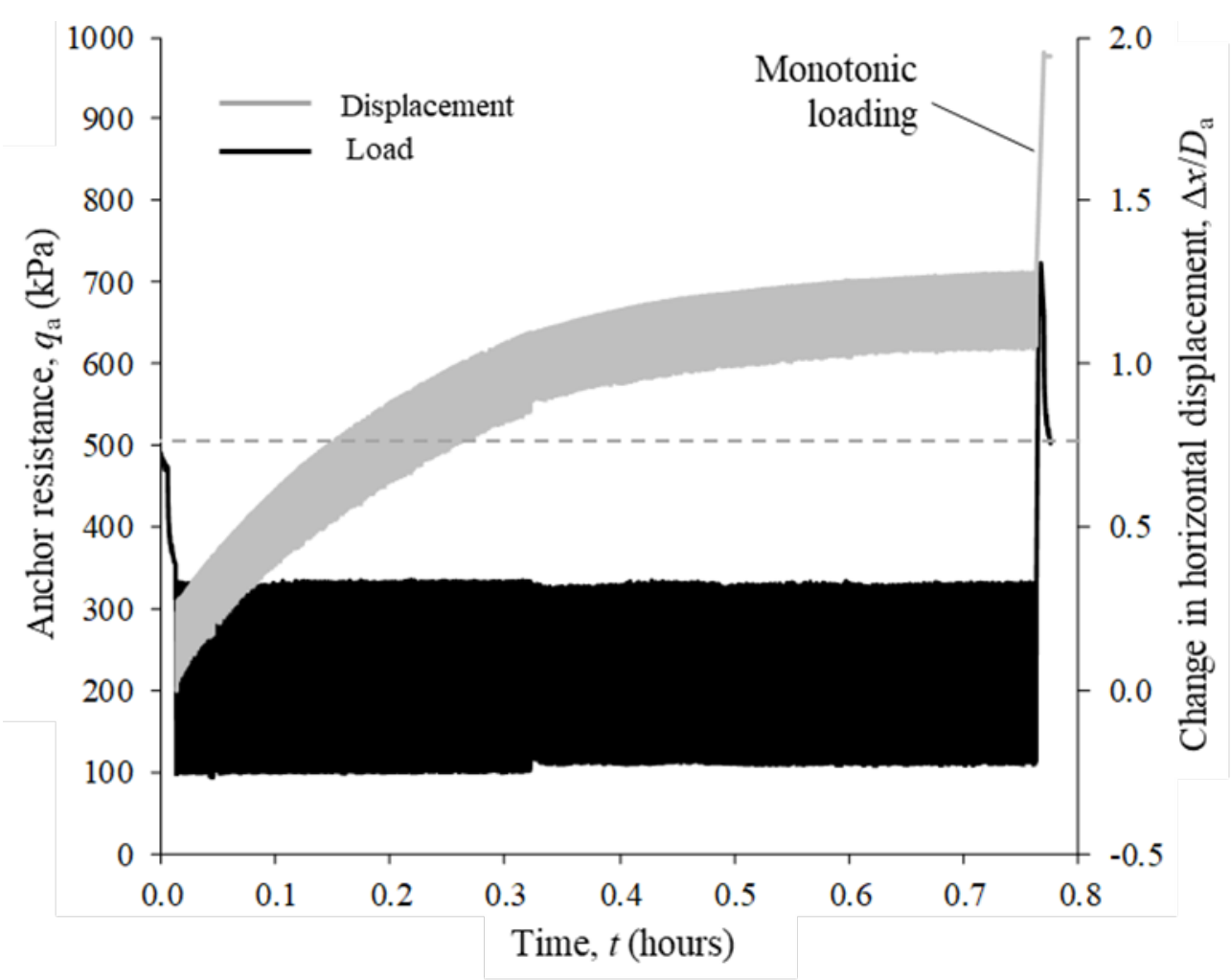

(b) 


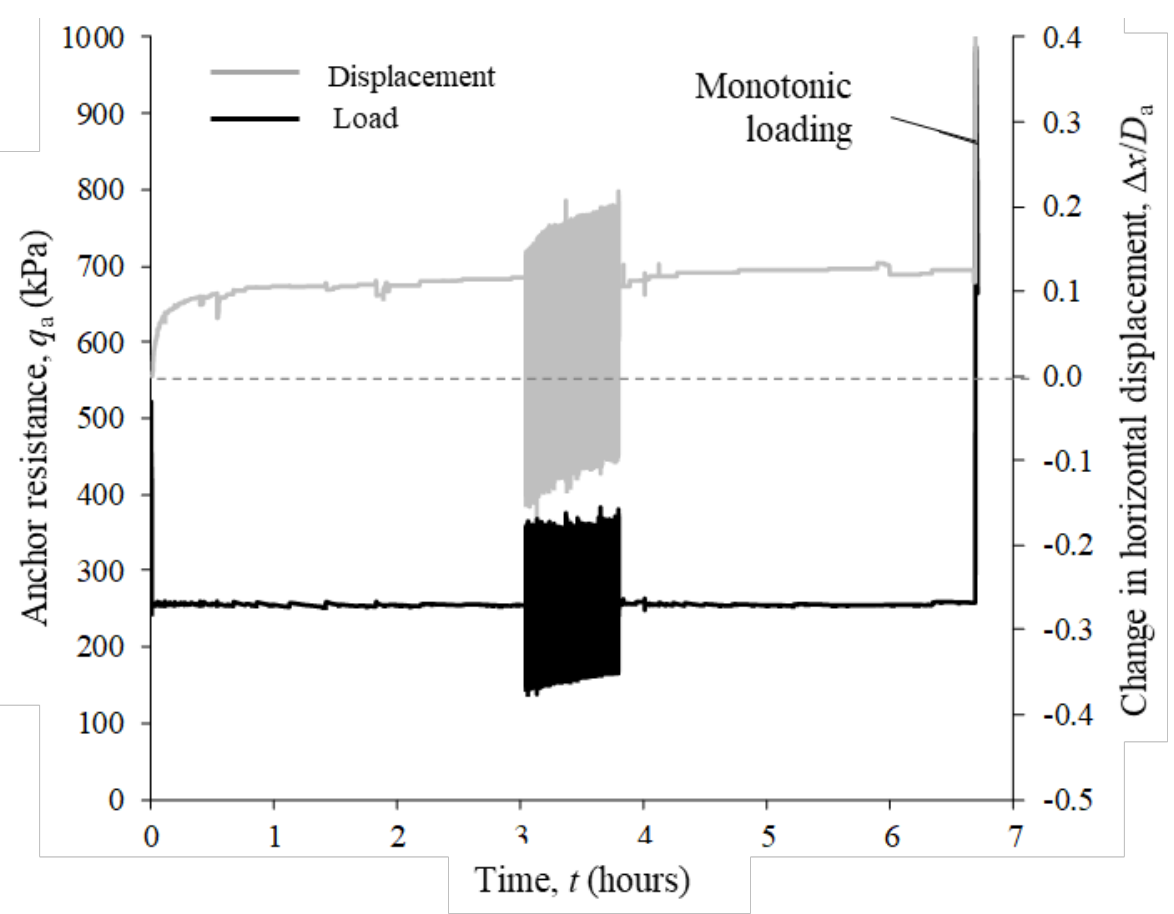

(c)

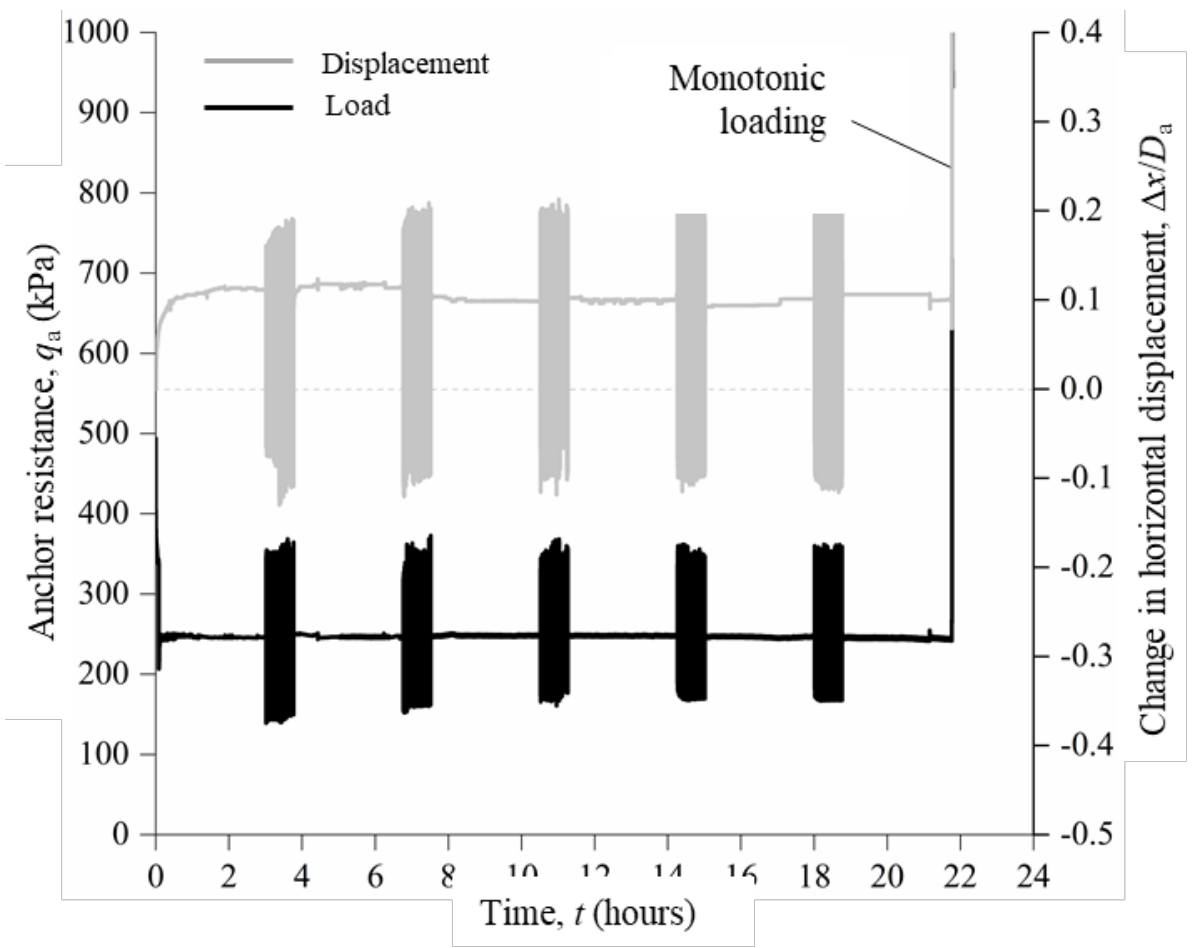

(d)

Figure 11 Maintained and cyclic loading sequence and the corresponding anchor displacement response: (a) Test 1; (b) Test 2; (c) Test 3; (4) Test 4 


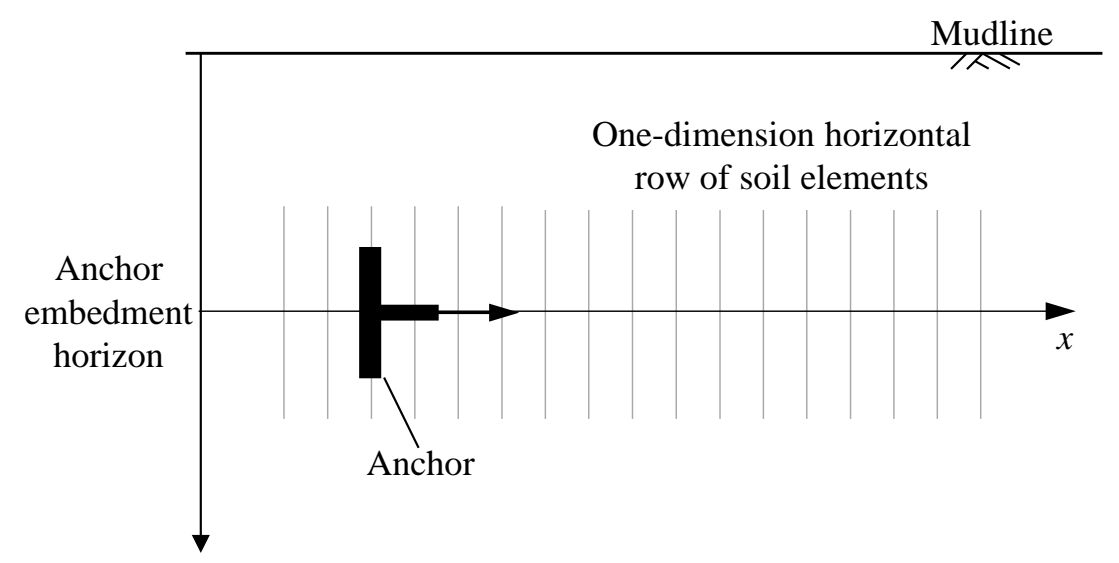

Soil depth, $z$

(a)

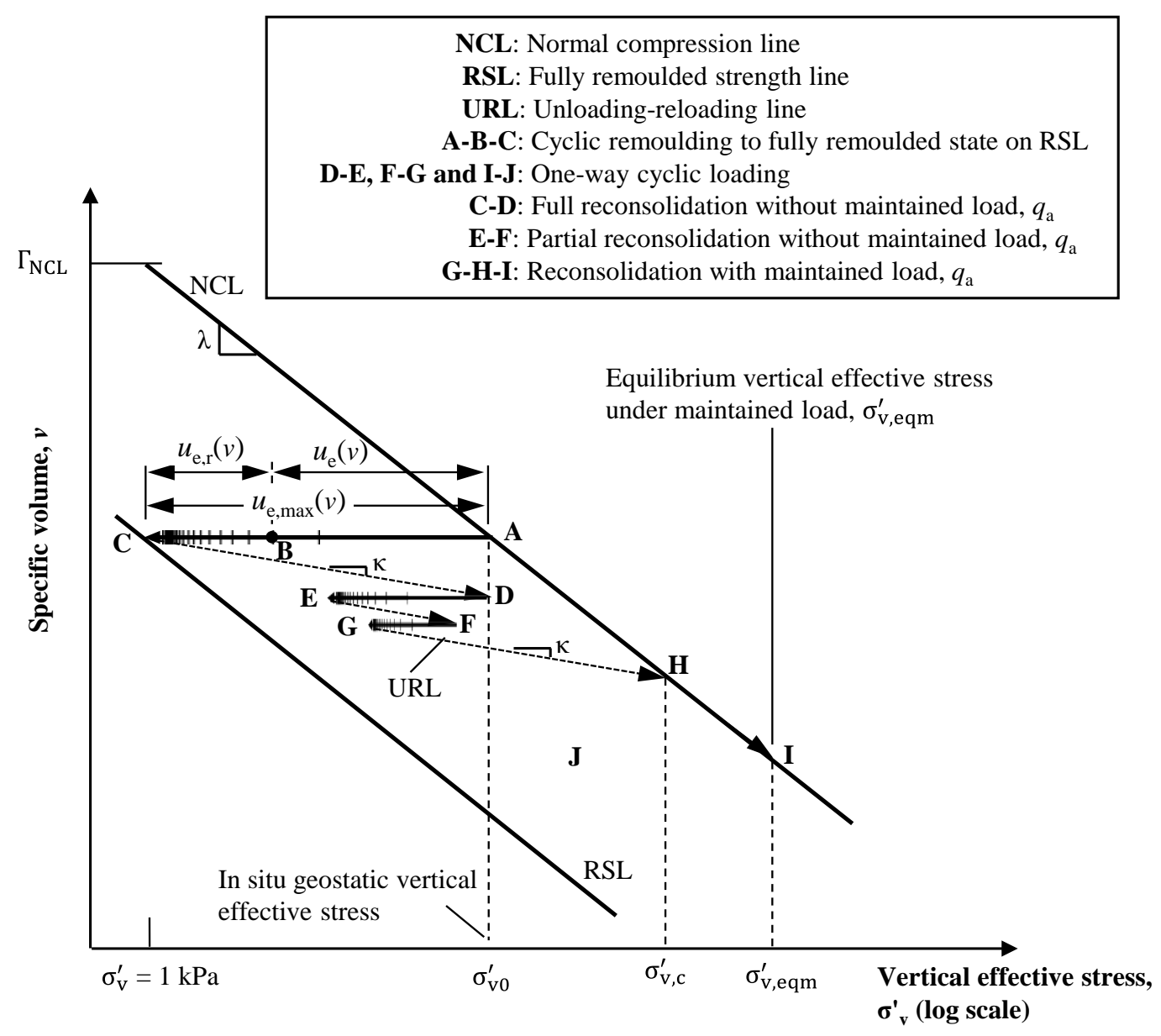

(b)

Figure 12 Effective stress framework: (a) one-dimension horizontal row of soil elements for this study; (b) effective stress paths due to remoulding, cyclic loading, reconsolidation and maintained load 

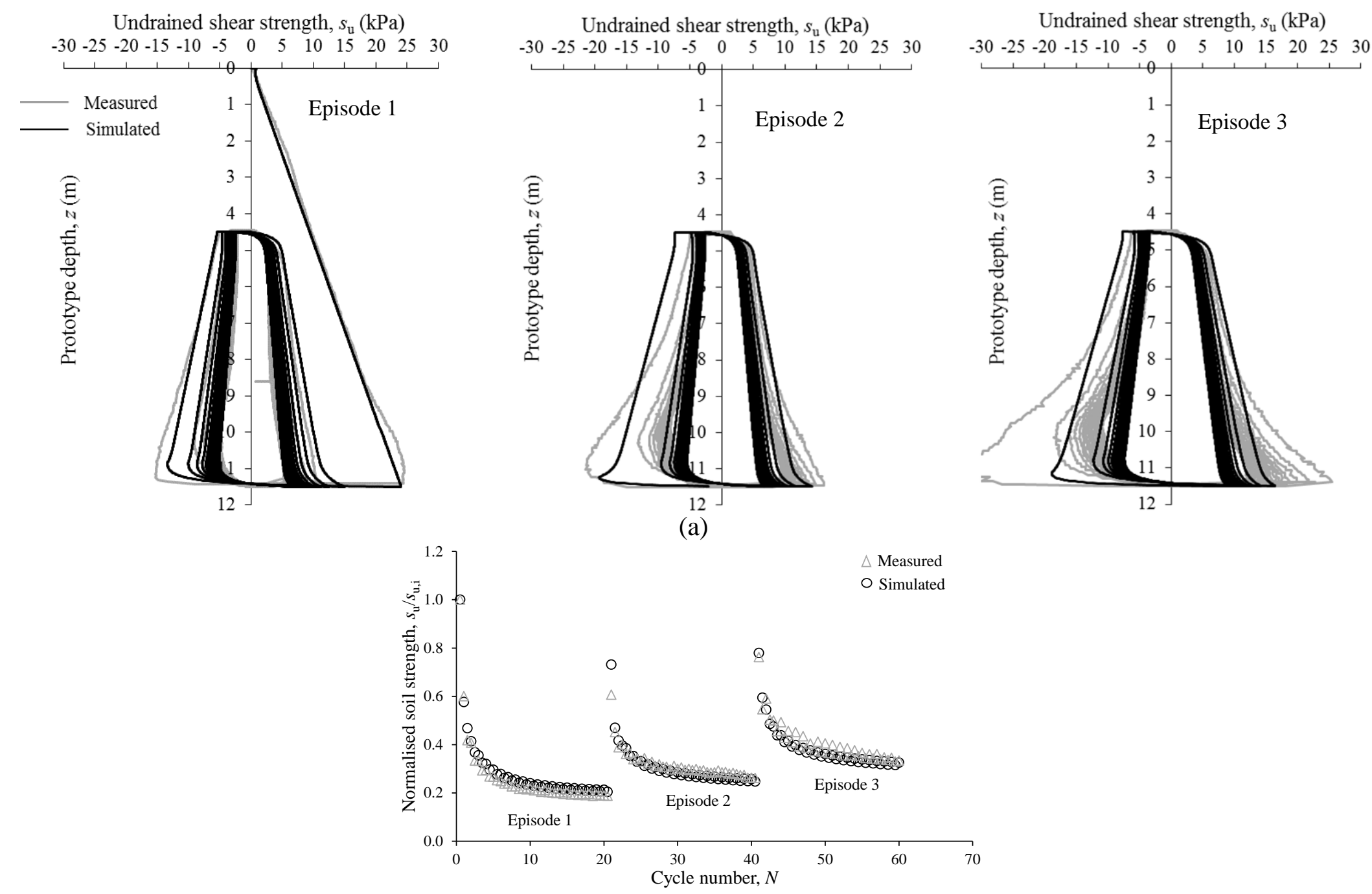

(b)

Figure 13 Comparison of experimental and simulated episodic cyclic T-bar: (a) depth profiles of undrained shear strength; (b) evolution of normalised soil strength, $s_{\mathrm{u}} / s_{\mathrm{u}, \mathrm{i}}$, during and after cycles at the mid-depth of the cycles 
823

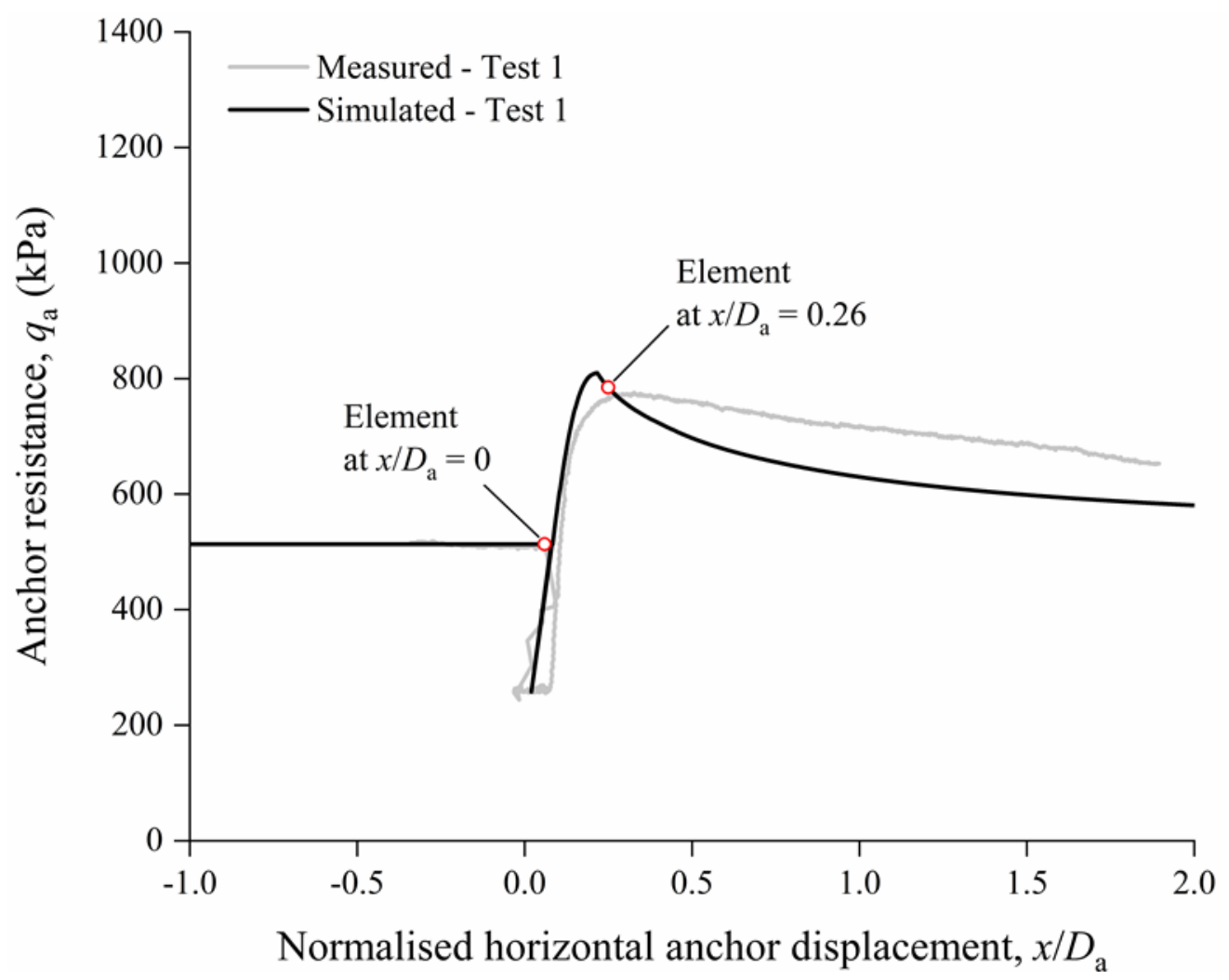

(a)

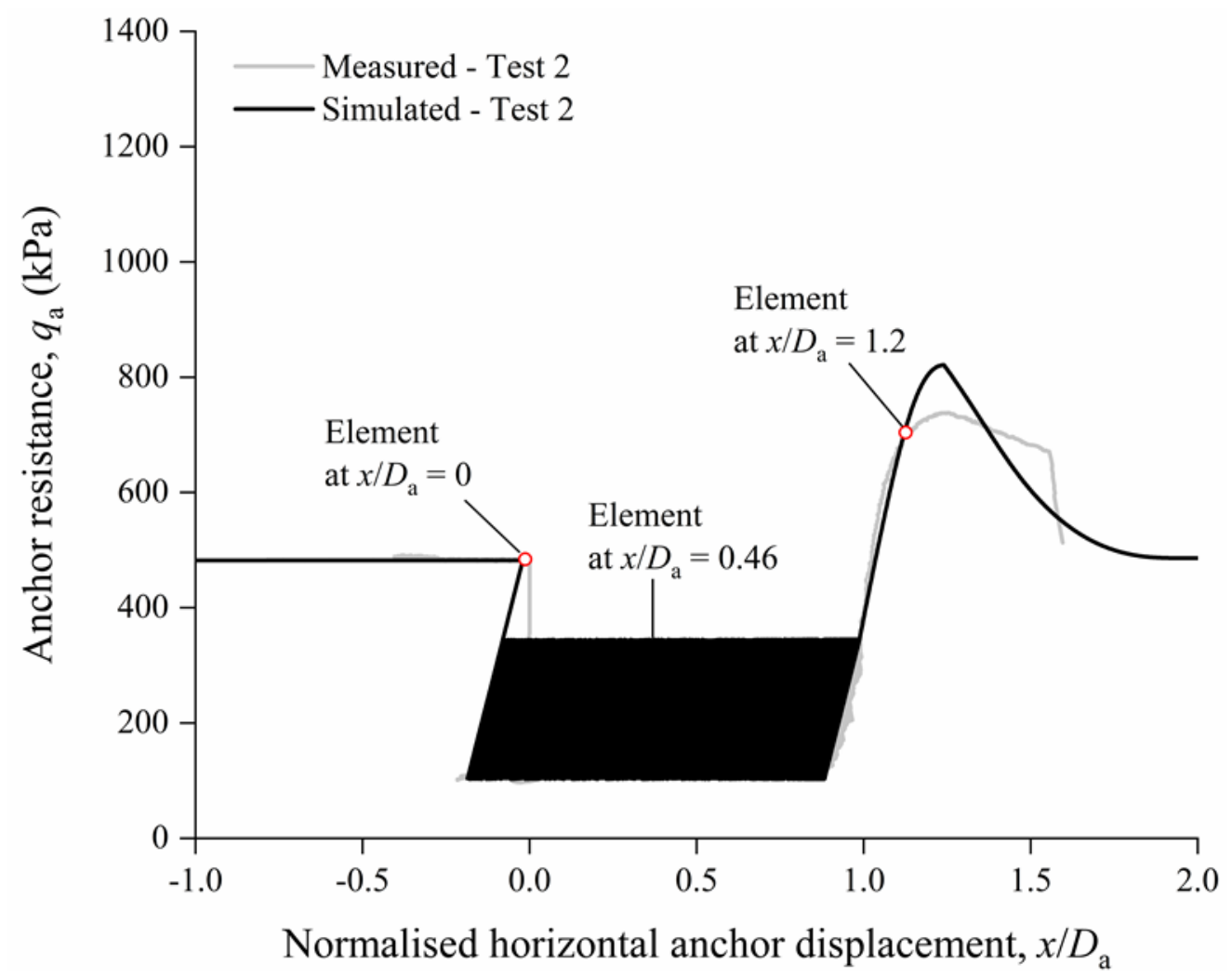

(b) 


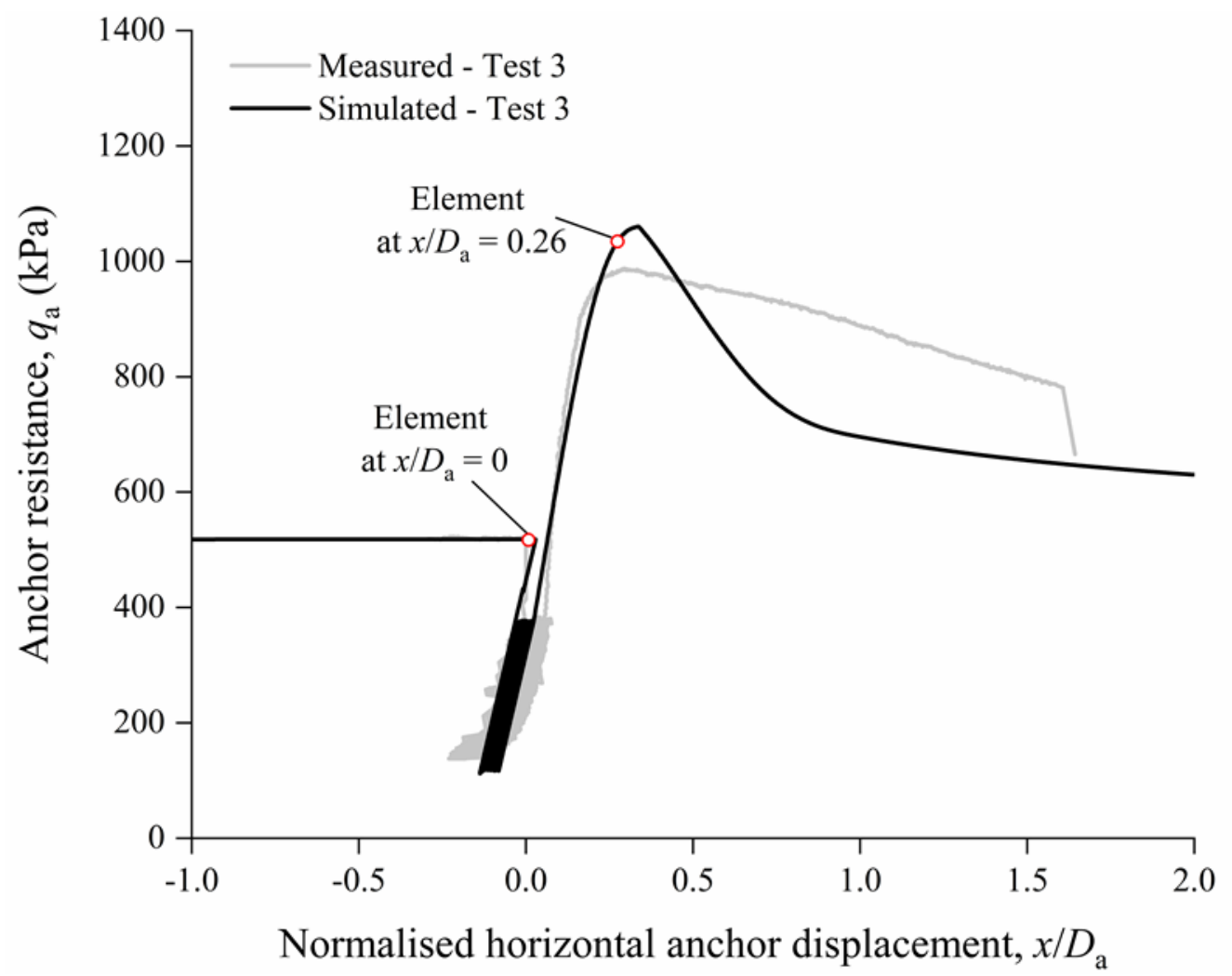

(c)

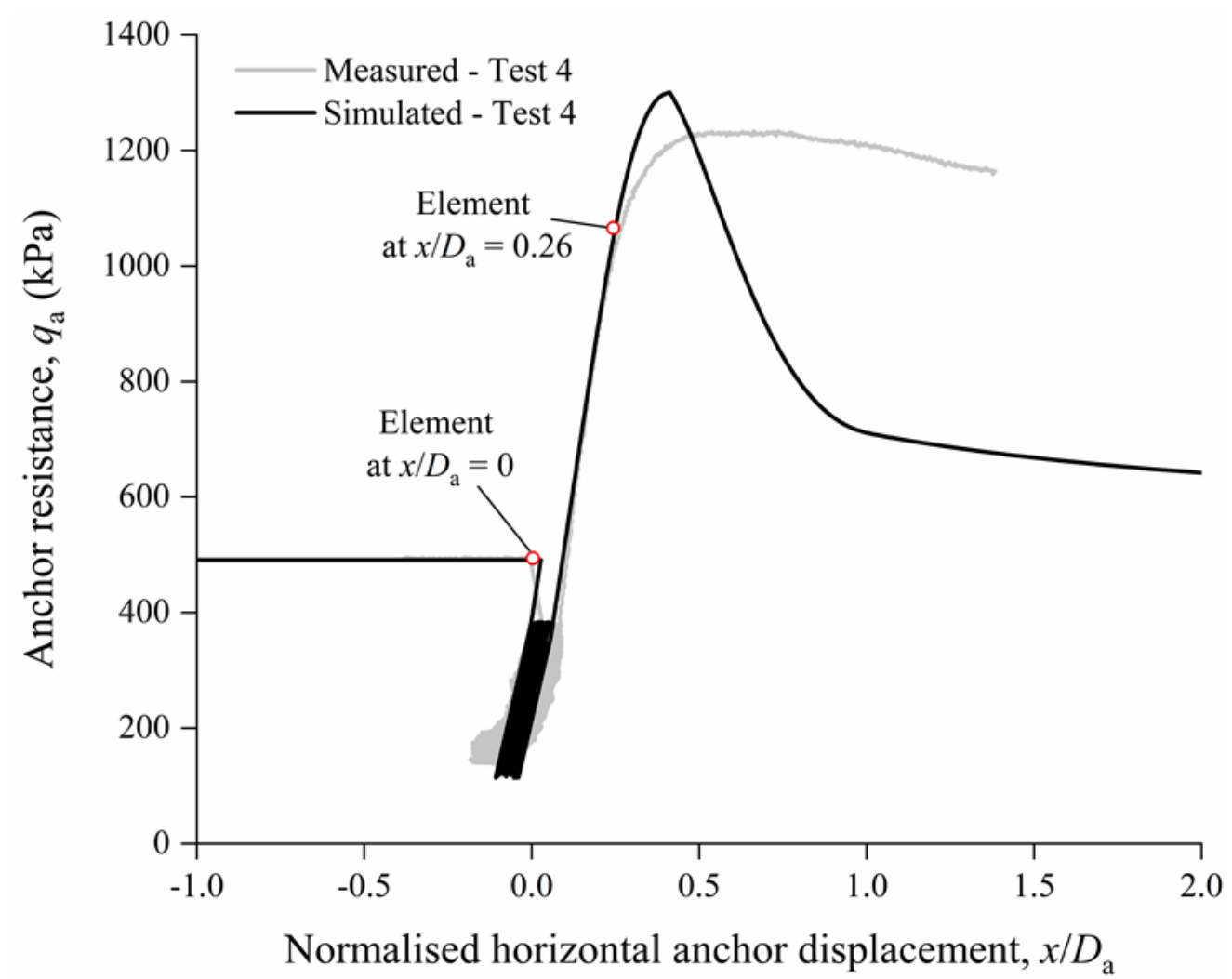

(d) 


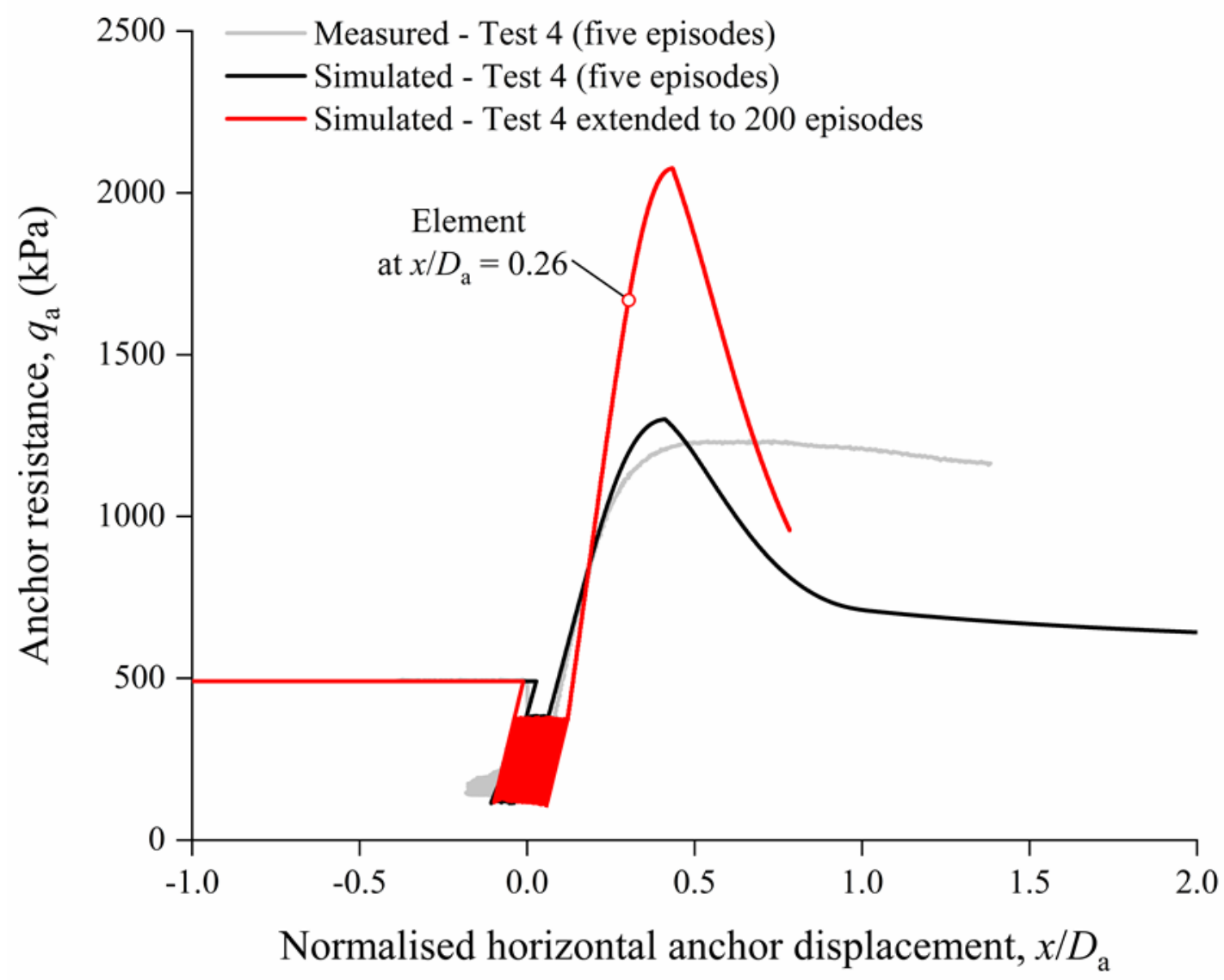

(e)

Figure 14 Experimental and simulated anchor capacities: (a) Test 1; (b) Test 2; (c) Test 3;

(d) Test 4; (e) Test 4 extended to 200 episodes 


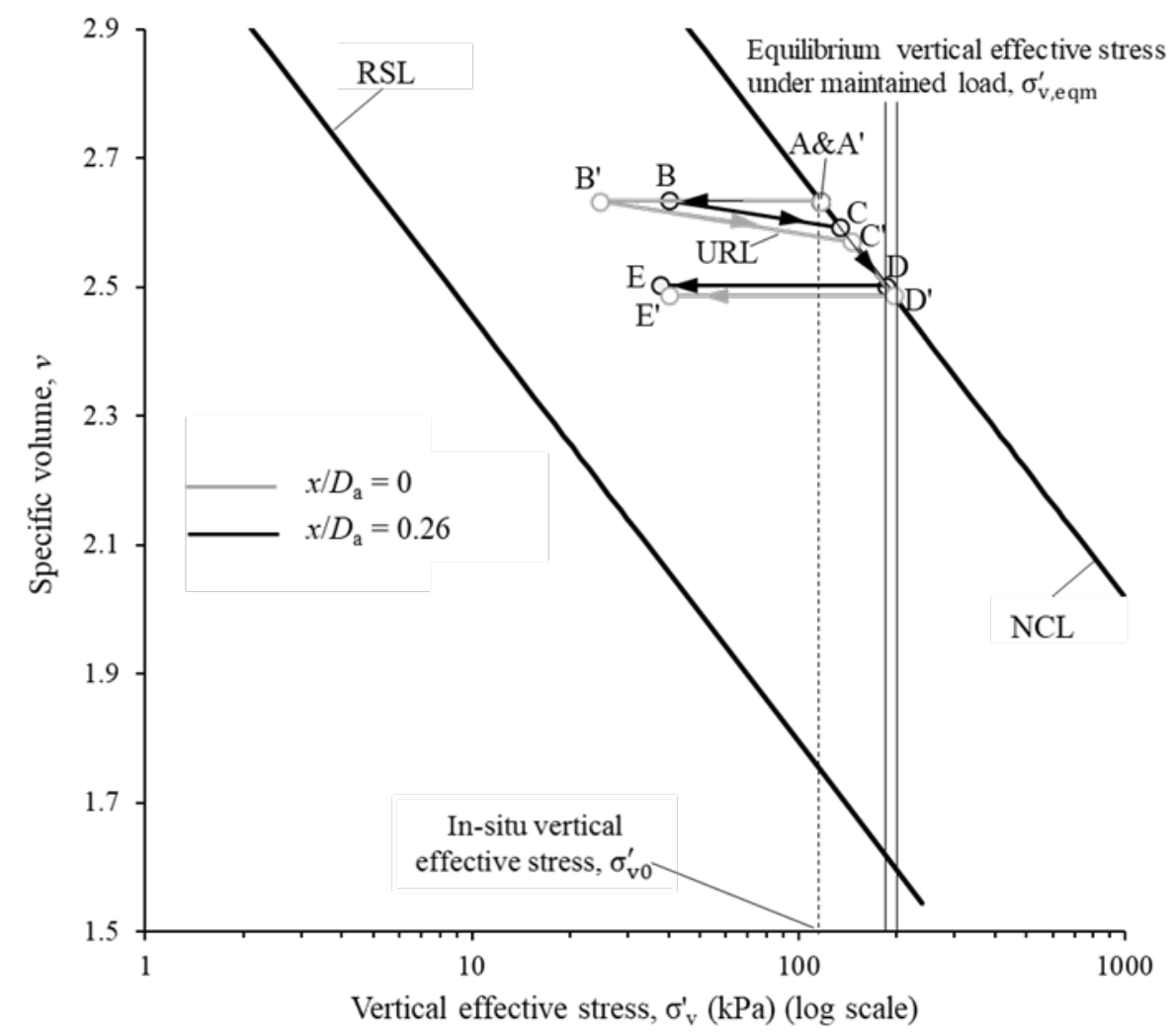

(a)

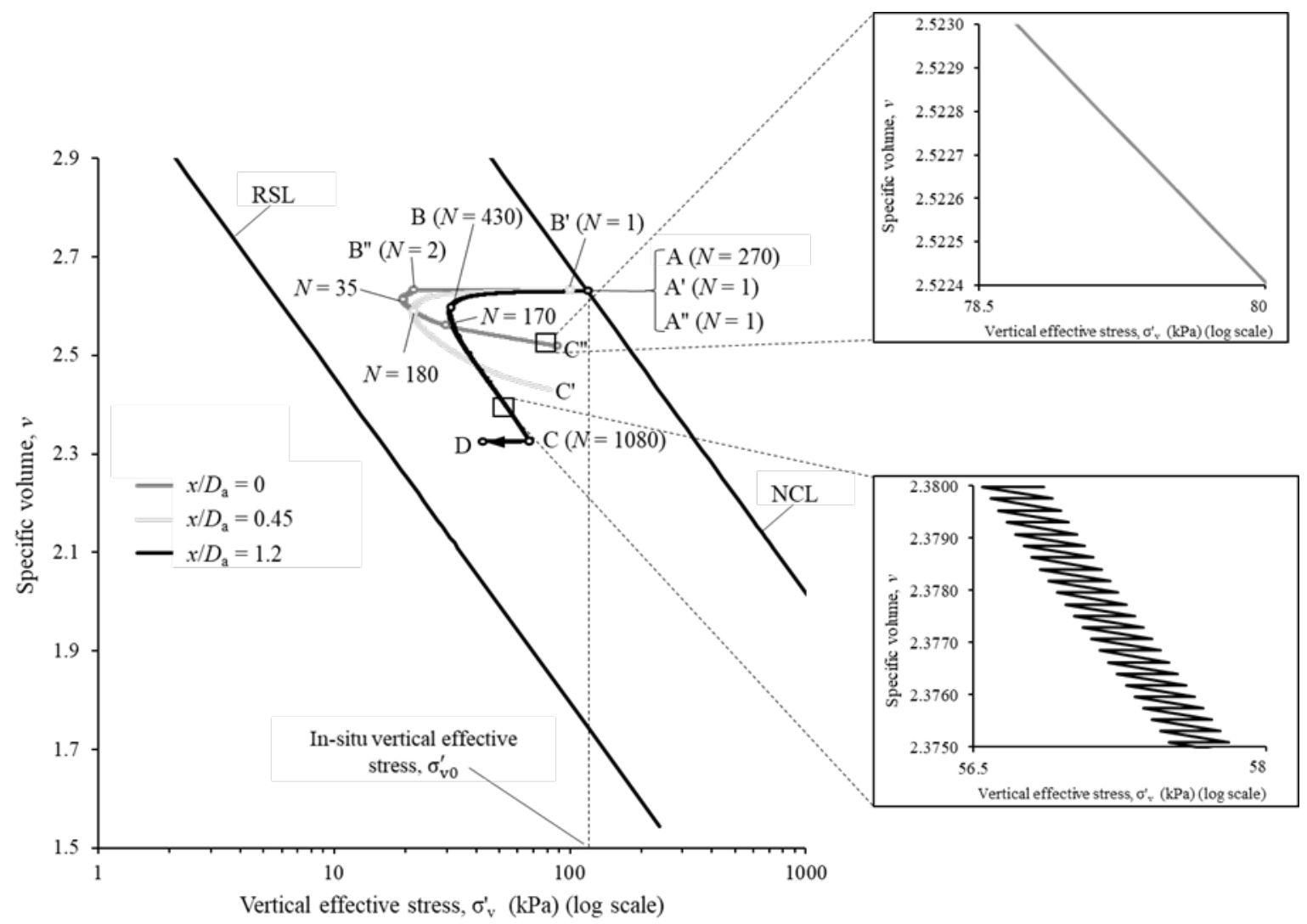

(b) 


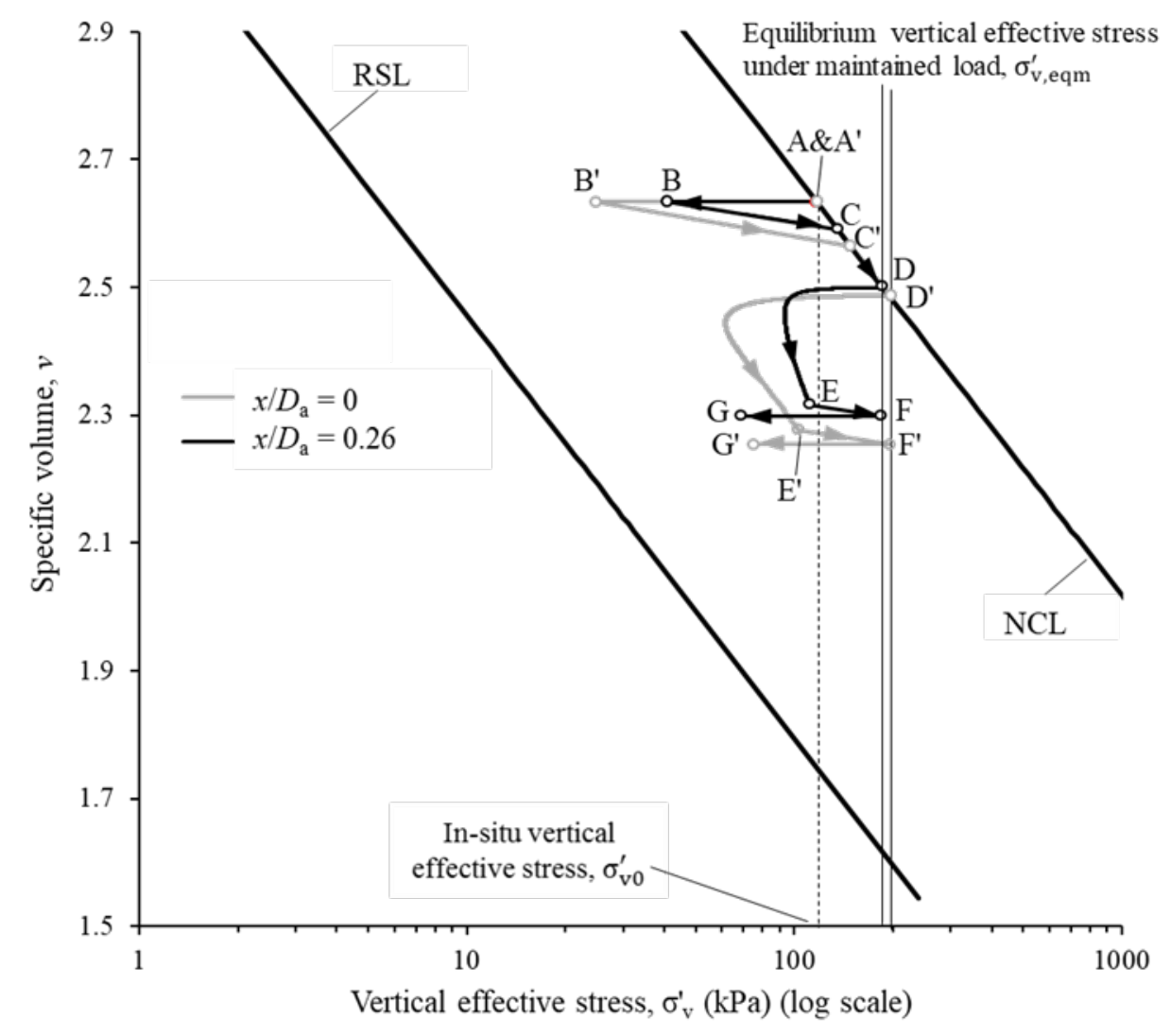

(c)

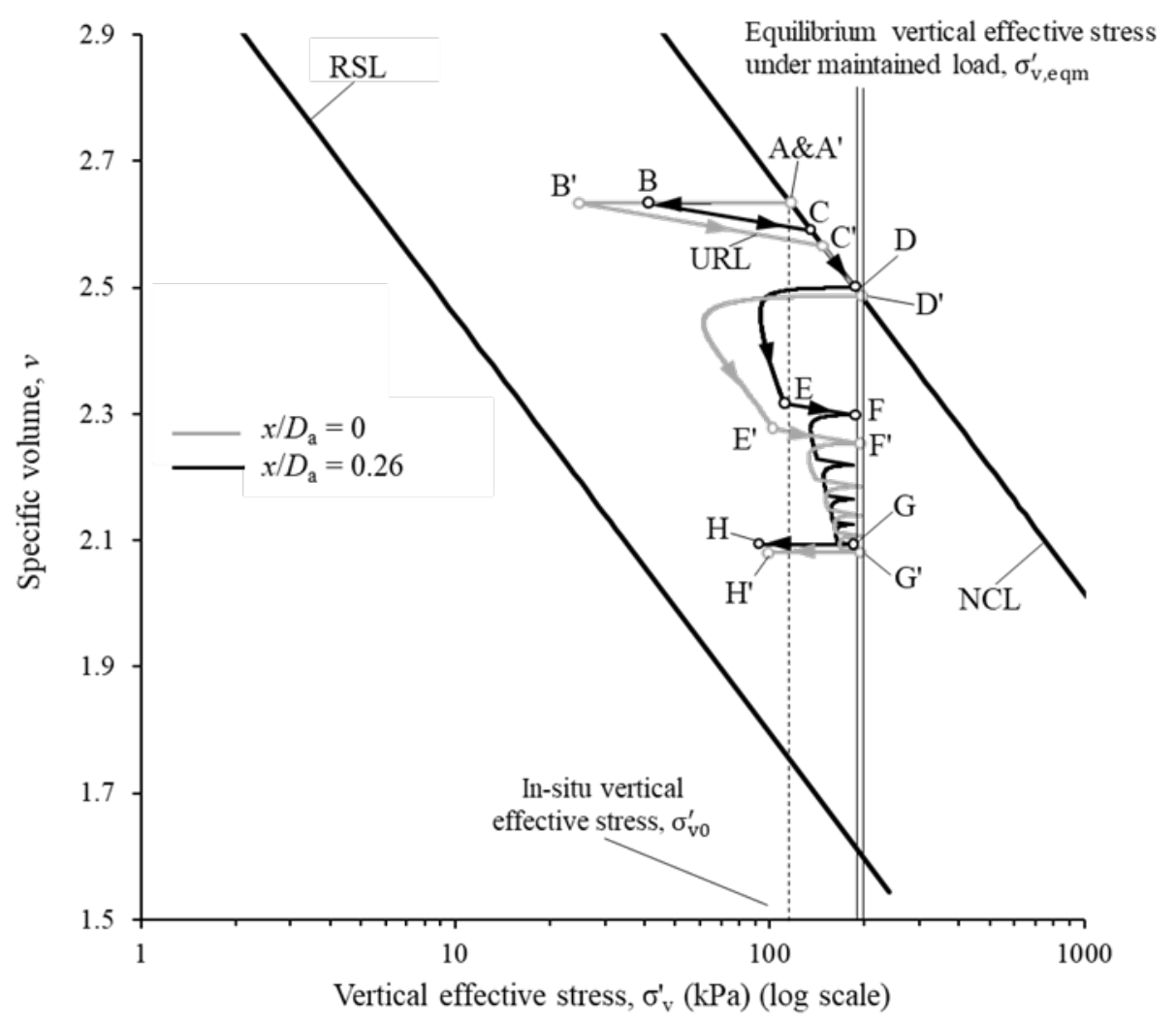

(d) 


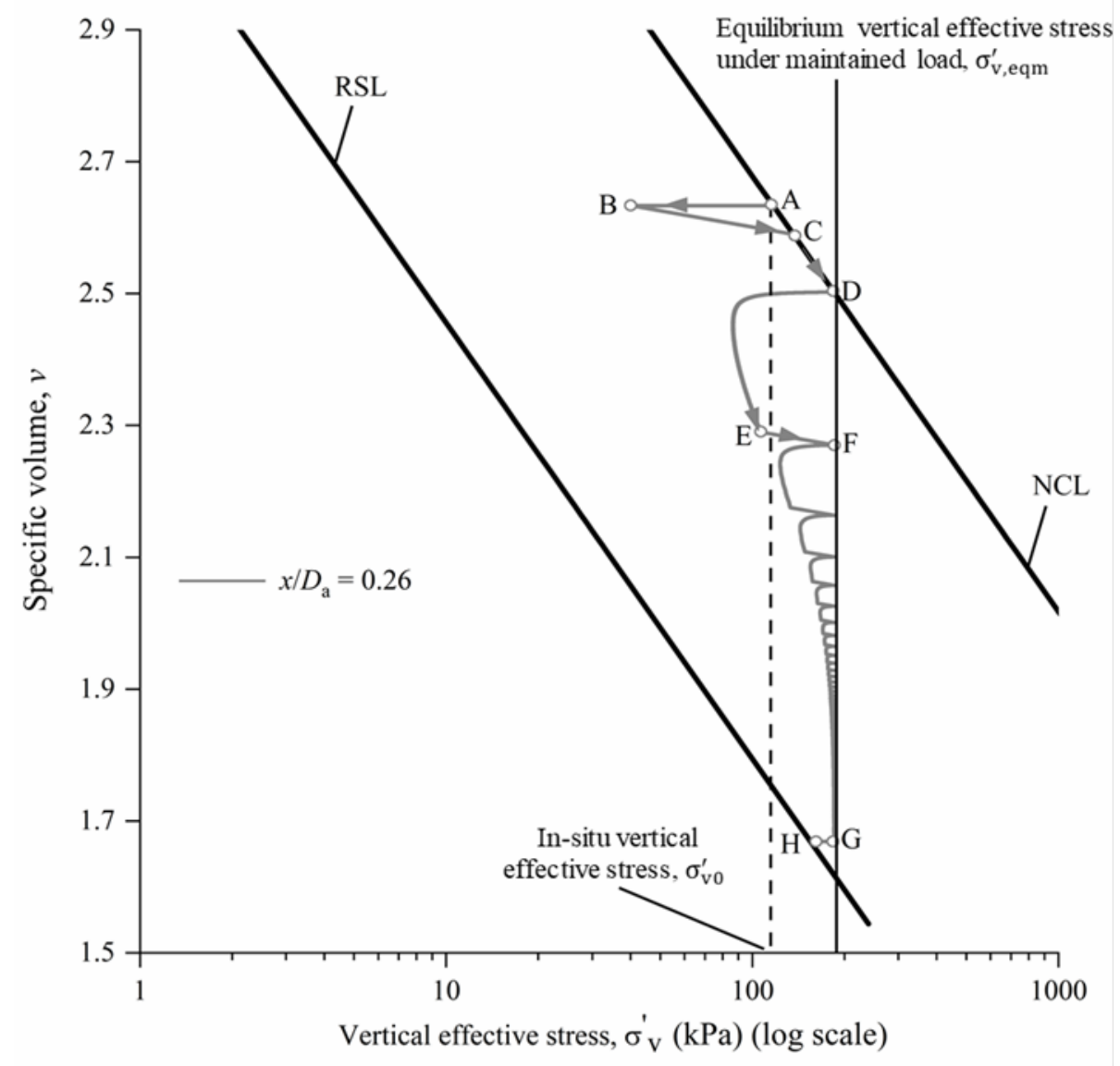

(e)

Figure 15 Effective stress paths: (a) at $z / D_{\mathrm{a}}=0$ and 0.26 for Test 1 ; (b) at $z / D_{\mathrm{a}}=0,0.46$ and 1.2 for Test 2; (c) at $z / D_{\mathrm{a}}=0$ and 0.26 for Test 3; (d) at $z / D_{\mathrm{a}}=0$ and 0.26 for Test 4 ; (e) at $z / D_{\mathrm{a}}=0.26$ for an extended simulation of Test 4 (involving 200 episodes) 
Table 1 Properties of the calcareous silt (from Chow et al. 2019)

\begin{tabular}{c|c}
\hline Property & Value \\
\hline Liquid limit, LL (\%) & 67 \\
\hline Plastic limit, PL (\%) & 39 \\
\hline Specific gravity, $G_{s}$ & 2.71 \\
\hline Slope of normal consolidation line, $\lambda$ & 0.287 \\
\hline Slope of swelling line, $\kappa$ & 0.036 \\
\hline Specific volume, $v$, at $\sigma^{\prime}{ }_{\mathrm{v}}=1 \mathrm{kPa}$ on $\mathrm{NCL}, \Gamma_{\mathrm{NCL}}$ & 4 \\
\hline Carbonate content, $\mathrm{CaCO}_{3}(\%)$ & 73.29 \\
\hline
\end{tabular}

832

833

834

835

836

837

838

839

840

841

842

843

844

845

846

847

848

849

850

851

852

853

854

855

856

857

858

859

860

861

862

863

864 
Improvements in plate anchor capacity due to cyclic and maintained loads combined with consolidation

Table 2 Summary of anchor tests: loading sequences, test results and simulation results

\begin{tabular}{|c|c|c|c|c|c|c|c|c|c|c|}
\hline \multirow[b]{2}{*}{ Test } & \multicolumn{3}{|c|}{ Episodic loading regime } & \multirow[b]{2}{*}{$\begin{array}{l}\text { Number } \\
\text { of } \\
\text { episodes }\end{array}$} & \multicolumn{4}{|c|}{ Test results } & \multirow[b]{2}{*}{$\begin{array}{l}\text { Simulated } \\
\text { peak anchor } \\
\text { capacity } \\
(\mathrm{kPa})\end{array}$} & \multirow[b]{2}{*}{$\begin{array}{l}\text { Ratio of } \\
\text { simulated to } \\
\text { measured } \\
\text { capacity }\end{array}$} \\
\hline & $\begin{array}{c}\text { Maintained } \\
\text { load }\end{array}$ & $\begin{array}{c}\text { One-way } \\
\text { cyclic loading }\end{array}$ & $\begin{array}{l}\text { Maintained } \\
\text { load }\end{array}$ & & $\begin{array}{c}\text { Initial } \\
\text { anchor } \\
\text { capacity, } \\
q_{\mathrm{a}, \mathrm{uu}} \\
(\mathrm{kPa})\end{array}$ & $\begin{array}{c}\text { Anchor } \\
\text { capacity } \\
\text { factor, } \\
N_{\text {c,a }}\end{array}$ & $\begin{array}{l}\text { Final } \\
\text { anchor } \\
\text { capacit } \\
\mathrm{y}(\mathrm{kPa})\end{array}$ & $\begin{array}{l}\text { Anchor } \\
\text { capacity } \\
\text { increase }\end{array}$ & & \\
\hline 1 & $\begin{array}{l}t_{\mathrm{c}}=3 \mathrm{hrs} \\
\text { at } 0.5 q_{\mathrm{a}, \mathrm{uu}}\end{array}$ & - & - & 1 & 516 & 11.5 & $\begin{array}{c}q_{\mathrm{a}, \mathrm{cu}}= \\
780\end{array}$ & $\begin{array}{l}q_{\mathrm{a}, \mathrm{cu}} / q_{\mathrm{a}, \mathrm{uu}} \\
=1.51\end{array}$ & $q_{\mathrm{a}, \mathrm{cu}}=810$ & 1.04 \\
\hline 2 & 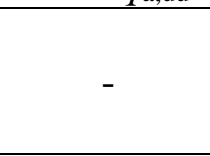 & $\begin{array}{c}N=1080 \text { cycles } \\
q_{\mathrm{a}}=0.25 q_{\mathrm{a}, \mathrm{uu}}- \\
0.75 q_{\mathrm{a}, \mathrm{uu}}\end{array}$ & - & 1 & 489 & 10.9 & $\begin{array}{c}q_{\mathrm{a}, \mathrm{ccu}}= \\
737\end{array}$ & $\begin{array}{l}q_{\mathrm{a}, \mathrm{ccu}} / q_{\mathrm{a}, \mathrm{uu}} \\
=1.50\end{array}$ & $q_{\mathrm{a}, \mathrm{ccu}}=821$ & 1.11 \\
\hline 3 & $\begin{array}{l}t_{\mathrm{c}}=3 \mathrm{hrs} \\
\text { at } 0.5 q_{\mathrm{a}, \mathrm{uu}}\end{array}$ & $\begin{array}{c}N=1080 \text { cycles } \\
q_{\mathrm{a}}=0.25 q_{\mathrm{a}, \mathrm{uu}}- \\
0.75 q_{\mathrm{a}, \mathrm{uu}}\end{array}$ & $\begin{array}{l}t_{\mathrm{c}}=3 \mathrm{hrs} \\
\text { at } 0.5 q_{\mathrm{a}, \mathrm{uu}}\end{array}$ & 1 & 521 & 11.6 & $\begin{array}{c}q_{\mathrm{a}, \mathrm{ccu}}= \\
990\end{array}$ & $\begin{array}{l}q_{\mathrm{a}, \text { сси }} / q_{\mathrm{a}, \text { uu }} \\
\quad=1.90\end{array}$ & $q_{\mathrm{a}, \mathrm{ccu}}=1063$ & 1.07 \\
\hline 4 & $\begin{array}{l}t_{\mathrm{c}}=3 \mathrm{hrs} \\
\text { at } 0.5 q_{\mathrm{a}, \mathrm{uu}}\end{array}$ & $\begin{array}{c}N=1080 \text { cycles } \\
q_{\mathrm{a}}=0.25 q_{\mathrm{a}, \text { uu }}- \\
0.75 q_{\mathrm{a}, \mathrm{uu}}\end{array}$ & $\begin{array}{l}t_{\mathrm{c}}=3 \mathrm{hrs} \\
\text { at } 0.5 q_{\mathrm{a}, \mathrm{uu}}\end{array}$ & 5 & 492 & 11.0 & $\begin{array}{c}q_{\mathrm{a}, \mathrm{ccu}}= \\
1230\end{array}$ & $\begin{array}{l}q_{\mathrm{a}, \text { сси }} / q_{\mathrm{a}, \text { uu }} \\
\quad=2.50\end{array}$ & $q_{\mathrm{a}, \mathrm{ccu}}=1304$ & 1.06 \\
\hline & & & & & & & & & Average & 1.07 \\
\hline
\end{tabular}


Improvements in plate anchor capacity due to cyclic and maintained loads combined with consolidation

Table 3 Summary of framework parameters used in the simulation of the episodic cyclic T-bar test

\begin{tabular}{|c|c|c|c|}
\hline Framework component & Parameter & Description & Value \\
\hline Geometry & $D$ & Diameter of the anchor & $0.75 \mathrm{~m}$ (prototype scale) \\
\hline Soil characteristics & $\begin{array}{c}\gamma^{\prime} \\
\text { OCR } \\
S_{\mathrm{t}, \mathrm{cyc}}\end{array}$ & $\begin{array}{c}\text { Effective unit weight } \\
\text { Over-consolidation ratio } \\
\text { Soil sensitivity } \\
\end{array}$ & $\begin{array}{c}5.2 \mathrm{kN} / \mathrm{m}^{3} \\
1 \\
5\end{array}$ \\
\hline Critical state mode & $\begin{array}{c}\lambda \\
\kappa \\
\left(s_{\mathrm{u}} / \sigma_{\mathrm{vo}}^{\prime}\right)_{\mathrm{NC}} \\
\Gamma_{\mathrm{NCL}} \\
\end{array}$ & $\begin{array}{c}\text { Compression index } \\
\text { Swelling index } \\
\text { Normally consolidated undrained strength ratio } \\
\text { Specific volume, } \mathrm{v} \text {, at } \sigma_{\mathrm{v}}^{\prime}=1 \mathrm{kPa} \text { on NCL }\end{array}$ & $\begin{array}{c}0.287 \\
0.036 \\
0.385 \\
4 \\
\end{array}$ \\
\hline $\begin{array}{l}\text { Excess pore pressure } \\
\text { generation }\end{array}$ & $\begin{array}{c}\varepsilon_{98} \\
p \\
\beta\end{array}$ & $\begin{array}{l}\text { Cumulative shear strain parameter } \\
\text { Shear strain rate parameter } \\
\text { Strain influence zone extent }\end{array}$ & $\begin{array}{l}100 \\
2.9 \\
1 D\end{array}$ \\
\hline Consolidation process & $\begin{array}{c}T_{50} \\
m\end{array}$ & $\begin{array}{c}\text { Non-dimensional time for } 50 \% \text { consolidation } \\
\text { Embedment level parameter }\end{array}$ & $\begin{array}{l}0.09 \\
1.05\end{array}$ \\
\hline $\begin{array}{l}\text { General soil strength and } \\
\text { stiffness response }\end{array}$ & $\begin{array}{c}\Phi \\
\alpha \\
K_{\max } \\
\zeta\end{array}$ & $\begin{array}{c}\text { Lumped strength parameter } \\
\text { Strength influence zone extent } \\
\text { Maximum tangent stiffness } \\
\text { Power law parameter for strength mobilisation }\end{array}$ & $\begin{array}{c}1.62 \\
1 D \\
32.5 \\
0.32 \\
\end{array}$ \\
\hline
\end{tabular}


Table 4 Summary of framework parameters used in the simulation of the anchor tests

\begin{tabular}{|c|c|c|c|c|}
\hline $\begin{array}{c}\text { Framework } \\
\text { component }\end{array}$ & Parameter & Description & Value & Remarks \\
\hline Geometry & $D$ & Anchor diameter (prototype scale) & $5.25 \mathrm{~m}$ & - \\
\hline $\begin{array}{c}\text { Soil } \\
\text { characteristics }\end{array}$ & $\begin{array}{c}\gamma^{\prime} \\
\text { OCR } \\
S_{\mathrm{t}, \mathrm{cyc}} \\
C_{\mathrm{op}}\end{array}$ & $\begin{array}{l}\text { Effective unit weight } \\
\text { Over-consolidation ratio } \\
\text { Soil sensitivity } \\
\text { Coefficient of consolidation }\end{array}$ & $\begin{array}{c}5.2 \mathrm{kN} / \mathrm{m}^{3} \\
1 \\
5 \\
4 \mathrm{~m}^{2} / \text { year }\end{array}$ & $\begin{array}{l}\text { - } \\
\text { Normally consolidated soil sample for this study } \\
\text { Measured by cyclic T-bar test } \\
\text { Measured by piezo-foundation test }\end{array}$ \\
\hline $\begin{array}{l}\text { Critical state } \\
\text { mode }\end{array}$ & $\begin{array}{c}\lambda \\
\kappa \\
\left(s_{\mathrm{u}} / \sigma_{\mathrm{vo}}^{\prime}\right)_{\mathrm{NC}} \\
\Gamma_{\mathrm{NCL}} \\
\end{array}$ & $\begin{array}{c}\text { Compression index } \\
\text { Swelling index } \\
\text { Normally consolidated undrained strength ratio } \\
\text { Specific volume, } \mathrm{v} \text {, at } \sigma_{\mathrm{v}}^{\prime}=1 \mathrm{kPa} \text { on NCL }\end{array}$ & $\begin{array}{c}0.287 \\
0.036 \\
0.385 \\
4\end{array}$ & $\begin{array}{l}\qquad \lambda \text { defines the gradient of NCL } \\
\kappa \text { defines the gradient of URL } \\
\text { Based on an undrained shear strength gradient, } \mathrm{k}=2 \mathrm{kPa} / \mathrm{m} \text { and } \\
\text { effective unit weight, } \gamma^{\prime}=5.2 \mathrm{kN} / \mathrm{m}^{3}\end{array}$ \\
\hline $\begin{array}{l}\text { Excess pore } \\
\text { pressure } \\
\text { generation }\end{array}$ & $\begin{array}{c}\varepsilon_{98} \\
p \\
\beta\end{array}$ & $\begin{array}{l}\text { Cumulative shear strain parameter } \\
\text { Shear strain rate parameter } \\
\text { Strain influence zone extent }\end{array}$ & $\begin{array}{c}100 \\
2.9 \\
0.5 D\end{array}$ & $\begin{array}{c}\varepsilon_{98} \text { and } p \text { for excess pore pressure generation in Equation } 7 \\
\text { Selected to define the shear strain influence zone, as informed by } \\
\text { clay failure mechanisms (Yu et al., 2011). }\end{array}$ \\
\hline $\begin{array}{c}\text { Consolidation } \\
\text { process }\end{array}$ & $\begin{array}{c}T_{50} \\
m\end{array}$ & $\begin{array}{c}\text { Non-dimensional time for } 50 \% \text { consolidation } \\
\text { Embedment level parameter }\end{array}$ & $\begin{array}{l}0.07 \\
0.92\end{array}$ & $T_{50}$ and $m$ for excess pore pressure dissipation via Equation 9 \\
\hline $\begin{array}{l}\text { General soil } \\
\text { strength and } \\
\text { stiffness } \\
\text { response }\end{array}$ & $\begin{array}{l}\alpha \\
K_{\max } \\
\zeta\end{array}$ & $\begin{array}{c}\text { Lumped strength parameter } \\
\text { Strength influence zone extent } \\
\text { Maximum tangent stiffness } \\
\text { Power law parameter for strength mobilisation }\end{array}$ & $\begin{array}{l}1.62 \\
0.5 D \\
210 \\
4.55\end{array}$ & $\begin{array}{l}\text { Used to calculate the undrained shear strength from the current } \\
\text { vertical effective stress via Equation } 10 \\
\text { Selected to define the strength influence zone, as informed by clay } \\
\text { failure mechanisms (Yu et al., 2011). } \\
\text { Used to calculate effective tangent stiffness during soil strength } \\
\text { mobilisation via Equation } 12\end{array}$ \\
\hline
\end{tabular}

